\title{
Investigation of different dietary-fibre-ingredients for the design of a fibre enriched bread formulation low in FODMAPs based on wheat starch and vital gluten
}

\author{
Jonas J. Atzler ${ }^{1} \cdot$ Aylin W. Sahin $^{1} \cdot$ Eimear Gallagher $^{2}$ (D) Emanuele Zannini ${ }^{1}$ (i) $\cdot$ Elke K. Arendt ${ }^{1,3}$ (1)
}

Received: 29 November 2020 / Revised: 13 April 2021 / Accepted: 17 April 2021 / Published online: 26 May 2021

(c) The Author(s) 2021

\begin{abstract}
Consumption of fermentable oligo-, di-, monosaccharides and polyols (FODMAPs) often induces symptoms of irritable bowel syndrome (IBS). Since FODMAPs and dietary fibre (DF) share certain characteristics, IBS-patients have a limited intake of DF. Therefore, enrichment of a low FODMAP model bread (based on $84 \%$ wheat starch and $16 \%$ vital gluten) with various fibres (bamboo, cellulose, psyllium, guar gum) in two different concentrations ( $3 \mathrm{~g} / 100 \mathrm{~g}$ and $6 \mathrm{~g} / 100 \mathrm{~g}$ ) was investigated. Physico-chemical properties of doughs and breads were analysed (fermentation quality, gluten development, specific volume and hardness), as well as the release of reducing sugars during in vitro digestion. High performance anion exchange chromatography with coupled pulsed amperometric detection (HPAEC-PAD) was used to determine the FODMAP levels (contents of mannitol, sorbitol, fructose in excess of glucose, fructans and $\alpha$-galactooligosaccharides) of both dough and bread. Prototypes were compared with wheat flour-based breads (bakers' flour with and without wheat bran addition) to assess the performance of these prototypes. Prototypes showed a decreased quality compared to a baker's flour control, however, a quality comparable to commercial wheat bran breads was found. This in combination with a lower release of reducing sugars during in vitro digestion underline the potential of fibre enriched breads as part of a healthier and more palateable low FODMAP diet. Furthermore, this study highlights the importance of the type (viscous and insoluble) and the concentration of fibres used. Application of psyllium in a concentration of $3 \mathrm{~g} / 100 \mathrm{~g}$ showed the most beneficial impact on both physical (specific volume, hardness after $0 \mathrm{~h}$ and $24 \mathrm{~h}$ ) and nutritional aspects of bread.
\end{abstract}

Keywords FODMAP $\cdot$ Irritable bowel syndrome $\cdot$ Dietary fibres $\cdot$ Functional foods

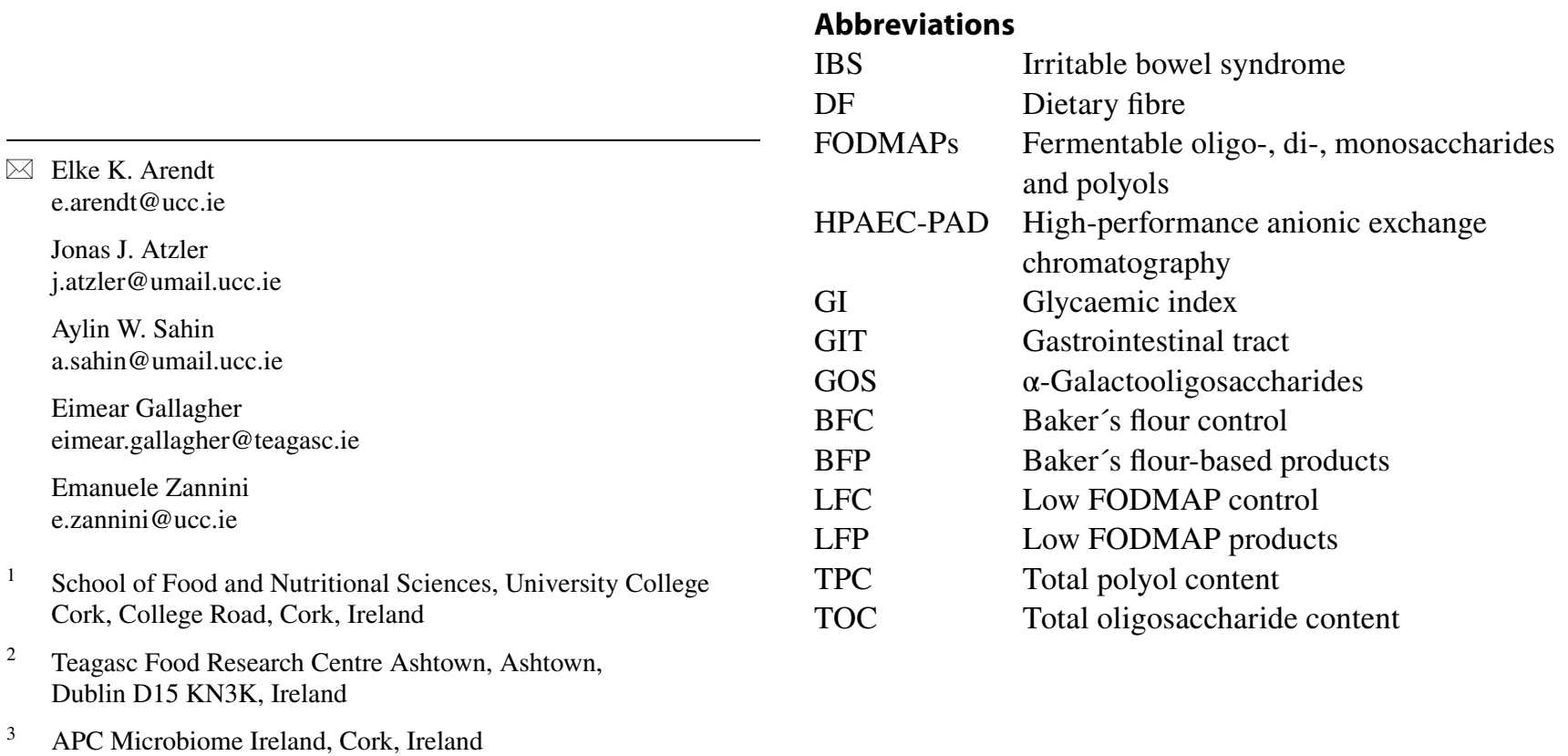




\section{Introduction}

Irritable bowel syndrome (IBS) is with a prevalence of $8-12 \%$ among the European population one of the most common bowel disorders [1]. Since symptoms of IBS can be caused by different factors, such as anxiety, stress and diet, the treatment uses various approaches including the adjustment of dietary habits [2]. Two highly recommended adjustments of dietary habits are to increase the intake of dietary fibre (DF) and to reduce the ingested amount of fermentable oligo-, di-, monosaccharides and polyols (FODMAPs) [3-7].

The European Food Safety Authority (EFSA) defines DF as carbohydrates which are not digestible in the human gastrointestinal tract (GIT) and have a scientifically proven beneficial effect on the GIT [8]. These effects include an increase of faecal mass, the support of the gut microbiota and a lowered glycaemic index (GI), which often lead to a relief of IBS symptoms [9-11]. However, the efficiency of the treatment and the impact on technical properties of the food products largely depend on the physical properties and the chemical structure of the fibre, such as solubility, viscosity and chain length [12]. DF can be divided into the following four main groups regarding their physicochemical properties and their fermentability: (a) soluble, highly fermentable DF; (b) intermediate soluble, fermentable DF; (c) insoluble, slowly fermentable DF and (d) insoluble, non-fermentable DF [7, 13]. Soluble DFs can also be separated according to their ability to form gel networks and their viscosity. The viscosity has been found to have a major beneficial effect on nutritional properties, e.g. lowering the total amount of cholesterol and the GI. Their ability to affect dough and bread properties, such as crumb hardness, in a positive way has been reported [7, 11, 14-17]. Insoluble fibres, such as cellulose and bamboo fibre, or wheat bran, additionally contribute to stool softening and an increased faecal mass. However, technological disadvantages of insoluble fibres, such as weakening of the gluten network or interfering with the gelatinisation of starch, have been researched and are reported [18-20]. Despite the general advantages of DF, clinical studies executed with IBS patients using wheat bran and psyllium showed either no relief or only a small improvement of symptoms [7, 13]. Therefore, a direct link between fibre intake and the improvement of IBS symptoms can not be confirmed.

FODMAPS are hypothesised to increase the amount of luminal water via their osmotic activity and to increase gas volume through microbial fermentation which leads to the expansion of the colon and therefore to the occurrence of IBS symptoms [21]. Cereals, such as wheat and rye, and cereal-based products contribute to the fibre intake, as well as to the FODMAP intake in the Western world [22-24]. Certain FODMAP compounds, such as fructans and $\alpha$-galactooligosaccharides are considered dietary fibres since they possess certain characteristics, such as fermentability, indigestibility in the human gut and a degree of polymerisation of at least three. Therefore, the number of beneficial fibres suitable for a low FODMAP diet is limited. These restrictions could subsequently cause a negative effect on the GIT, such as a lower rate of defaecation and alteration of the gut microbiome [25]. Therefore, the fortification of food products based on low FODMAP ingredients with various DFs, which are not considered to belong to the FODMAP group has a high research potential. In recent years the research regarding the FODMAP reduction investigated various bio-technological approaches. Three promising approaches to reduce the FODMAP content in cereal-based products are the application of yeasts, sourdoughs and food-grade enzymes which are able to degrade fructans, which is the most prominent FODMAP in cereals [23, 26-28]. The use of yeasts and sourdoughs possesses a large potential since both yeasts and sourdoughs are commonly used in baking. The hydrolysis of fructans via yeasts was reported for $S$. Cerevisiae which is one of the most commonly used yeast species. However, its ability to reduce the FODMAP content is limited and relatively slow compared to common proof times. Therefore, the use of other yeasts, such as K. Marxianus is preferred [27]. Sourdoughs composed of bacteria strains, such as S. mutans, L. paracasei, $L$. salivarius, which can produce $\beta$-fructofuranosidases have been proven to lower the amount of fructans in both wheat and rye-based breads [26]. Invertase and inulinase are two enzymes which have been proven to degrade fructans in cereals and could therefore be used for the production of foods low in FODMAPs [28]. All three methods have the advantage of specifically degrading fructans and galactooligosaccharides. However, the use of ingredients already low in FODMAPs possesses lower risk, since its use is not depending on fermentation time and temperature or the used concentration. Therefore, the use of low FODMAP ingredients and fibres could lead to products with an improved nutritional quality and a low risk of triggering IBS.

The aim of this study was to investigate the effect of two soluble (guar gum, psyllium) and two insoluble fibres (bamboo, cellulose) on the technological properties (specific volume, gluten-network development, crumb structure) and the in vitro starch digestion of a low FODMAP bread. Prototypes were compared to a baker's flour control bread and breads fortified with wheat bran, which are an example for commercial breads enriched with fibre. These controls and two different concentrations were used to develop a product that can meet consumers expectations 
and fulfill either the source of fibre $(3 \mathrm{~g} / 100 \mathrm{~g})$ or high in fibre $(6 \mathrm{~g} / 100 \mathrm{~g})$ claim according to Regulation (EC) No 1924/2006 [29].

\section{Material and methods}

\section{Materials}

Baker's flour and wheat bran were supplied by Unifood, UK and Odlums, Ireland. Salt was supplied by Glacia British Salt Ltd., UK; vegetable oil by Musgrave, Ireland; sugar by Siucra Nordzucker, Ireland; and dry yeast by Puratos, Belgium. Six different ingredients were used for the formulation of low FODMAP breads. Gluten-free wheat starch and vital gluten (NUTRALYS W) were purchased from Roquette France; DATEM (PANODAN A2020 MB) from DANISCO, UK; Novamyl 1500 MG from Novozymes, Denmark; HPMC from J.Rettenmaier\&Söhne GmbH, Germany; and ascorbic acid from the Healy Group, Ireland. Psyllium (VITACEL Psyllium P95), Powdered Cellulose (VITACEL L 600-30) and Bamboo Fibre (VITACEL BAF 200) were purchased from J. Rettenmaier\&Söhne GmbH, Germany; while Guar Gum was supplied by Cargill, France. Chemicals and reagents which were used have been purchased from SigmaAldrich (USA) if not specified otherwise. The standards and chemicals as described by Ispiryan, et al., 2019 were used for the FODMAP determination via HPAEC-PAD [30]. All components of the HPAEC-PAD system and the Thermo Scientific DionexIC Pure Water purification system were acquired from Dionex ThermoSientific, USA. Both pepsin and pancreatic $\alpha$-amylase were supplied by Sigma-Aldrich (USA). $\alpha$-Galactosidase (E-AGLANP), amyloglucosidase (E-AMGPD) and inulinase (E-FRMXPD) were purchased from Megazyme, Ireland.

\section{Determination of moisture content}

Moisture contents of the raw ingredients, doughs and the final products were analysed using the official AACC method 44-15.02 [31].

\section{Empirical dough analysis}

Properties of the baker's flour control (BFC) and a low FODMAP control (LFC), which is based on $84 \%$ starch and $16 \%$ vital gluten, were analysed. For the investigation of the influence of fibres on either baker's flour-based products (BFP) or low FODMAP products (LFP) either baker's flour or wheat starch were partially replaced with wheat bran or the respective fibre (psyllium, guar gum, bamboo fibre, cellulose). The amounts of fibre ingredients added were based on the fibre content specified by the supplier and were adjusted to reach concentrations of either $3 \mathrm{~g} / 100 \mathrm{~g}$ or $6 \mathrm{~g} / 100 \mathrm{~g}$ (source of fibre or high in fibre concentrations according to Regulation (EC) No 1924/2006 [29]). Moisture contents of mixed ingredients were calculated based on the moisture content of the single ingredients and the used percentage of ingredients.

\section{Farinograph}

Determination of the water absorption was executed by using the Farinograph (Brabender GmbH and Co KG, Germany). The procedure was carried out according to the official AACC method 54-21.02 [32]. Water content of wheatbased doughs was adjusted to a consistency of $(500 \pm 20$ FU) and flours based on low FODMAP breads were adjusted to a consistency of $(400 \pm 20 \mathrm{FU})$ Farinograph units. The determination of the water absorption of the LFPs was executed at $(400 \pm 20 \mathrm{FU})$ since preliminary trials for the LFC resulted in measurements of a maximum force of $(400 \pm 20$ FU). Therefore, a consistency of ( $500 \pm 20 \mathrm{FU})$ could not be reached with formulations based on the LFC and the lower force was used as a reference value.

\section{GlutoPeak}

The development and the strength of the gluten network were investigated using the GlutoPeak (Brabender GmbH and Co KG, Germany). Measurement of the properties of the gluten-network are based on the application of high shear forces to a suspension of the solid ingredients and water. For trials regarding the BFC, BFPs and LFPs fortified with psyllium and guar gum a 50/50 ratio between the dry sample and deionised water was used. Measurements were executed with this ratio since a ratio of 56/44 caused a maximum torque (MT) above $110 \mathrm{BE}$ and a peak maximum time (PMT) of $20 \mathrm{~s}$ for the formulations with a lower fibre content (Data not shown). The LFC and LFPs enriched with bamboo and cellulose were measured at a ratio of 56/44 between a dry sample and deionised water. A total weight of $18 \mathrm{~g}$ for the suspensions was used. Different weights for the solid sample and deionised water were used, since different ratios needed to be applied, either $9.00 \mathrm{~g}$ (50/50 ratio) or $10.08 \mathrm{~g}$ (56/44 ratio) were weighed in and were added to $9.00 \mathrm{~g}$ or $7.92 \mathrm{~g}$ of deionised water $\left(36^{\circ} \mathrm{C}\right)$. Weights of solid samples were based on a moisture content of $14 \%$ and weights were adjusted according to AACC 82-23.01 [33]. A mixing speed of $2750 \mathrm{rpm}$ and a maximum measuring time of 10 min were used. Temperature was kept at $36{ }^{\circ} \mathrm{C}$ during the measurements using a heated water circulation system. Measurements were stopped $60 \mathrm{~s}$ after reaching the maximum peak. Evaluation of the obtained curves was executed with the software provided by the manufacturer to obtain 
maximum Torque (MT; given in Brabender Units BU) and Peak Maximum Time (PMT, given in s).

\section{Rheofermentometer}

Dough development was investigated by detecting the production and retention of $\mathrm{CO}_{2}$ using the Rheofermentometer (Chopin, France). Three hundred grams of dough were prepared using the mixing procedure described for the bread-making process. Each dough was placed into the fermentation chamber and fermented at $30{ }^{\circ} \mathrm{C}$ for $180 \mathrm{~min}$. The fermentation chamber was locked and fixated using a cylindrical weight with a mass of $1500 \mathrm{~g}$. Evaluation of the fermentation is based on the maximum height $(\mathrm{Hm})$ of the dough reached during fermentation, the dough volume reached during the fermentation process (VTot) and the amount of carbon dioxide retained in the dough (given in \%).

\section{Bread making process and bread formulations}

Breads based on baker's flour have been prepared by using $2 \%$ salt, $1.5 \%$ sugar and $2 \%$ yeast related to the amount of baker's flour. Formulations of the various LFPs were based on the recipe of the LFC (Table 1). Recipes for the incorporation of fibre were calculated by replacing baker's flour or wheat starch with the amount of fibre necessary to reach a fibre content of $3 \mathrm{~g} / 100 \mathrm{~g}$ or $6 \mathrm{~g} / 100 \mathrm{~g}$. For the incorporation of fibre ingredients (wheat bran, psyllium, guar gum, bamboo fibre, cellulose) the fibre contents specified by the supplier have been used for these calculations. The water adjustment was based on the results obtained during Farinograph trials. Yeast was activated in $27^{\circ} \mathrm{C}$ tap water for $10 \mathrm{~min}$ and

Table 1 Base recipe for LFP based on the amounts of the sum of wheat starch and gluten

\begin{tabular}{llc}
\hline & \% based on recipe & $\begin{array}{l}\text { \% based on } \\
\text { starch and } \\
\text { gluten }\end{array}$ \\
\hline Wheat starch & 49.77 & 84.00 \\
Vital Gluten & 9.48 & 16.00 \\
DATEM & 0.15 & 0.25 \\
HPMC & 0.30 & 0.50 \\
Ascorbic Acid & 0.01 & 0.01 \\
Novamyl@ & 0.001 & 0.001 \\
Salt & 1.19 & 2.00 \\
Sugar & 0.89 & 1.50 \\
Yeast & 1.19 & 2.00 \\
Fat & 1.78 & 3.00 \\
Water* & 35.26 & 59.50 \\
Sum & $\mathbf{1 0 0}$ & $\mathbf{1 6 8 . 7 6}$ \\
\hline
\end{tabular}

Water amounts are based on the results obtained during Farinograph trials this suspension was subsequently added to the solid and premixed ingredients. Mixing of $2000 \mathrm{~g}$ dough was carried out using a Kenwood Chef mixer (Kenwood Manufacturing Co. Ltd., UK) at speed 1 and speed 2 for 1 and 7 min, respectively. A bulk fermentation over 15 min was performed in a proofer set to $85 \%$ relative humidity and $30^{\circ} \mathrm{C}$. The dough was divided into six loaves with a weight of $200 \mathrm{~g}$ each and moulded into shape. Loaves were proofed in tins for $60 \mathrm{~min}$. Breads were baked at $230{ }^{\circ} \mathrm{C}$ (top and bottom temperature) in a deck oven (MIWE Condo, Germany) for $30 \mathrm{~min}$ and steaming was used after loading $(700 \mathrm{~mL})$ and after baking $(400 \mathrm{~mL})$. After baking, breads were taken out of tins and cooled down at room temperature for $90 \mathrm{~min}$. All baking trials were conducted in triplicate and independently.

\section{Empirical bread analysis}

The specific volume of the loaves was measured using a Volscan Profiler (Stable Micro Systems, UK). Slices with a thickness of $25 \mathrm{~mm}$ were used for measuring the crumb structure and crumb hardness after $0 \mathrm{~h}$ and $24 \mathrm{~h}$. Number and area of cells were analysed using the C-Cell Imaging System (Calibre Control International Ltd., UK). For the determination of crumb hardness, a TA-XT2i Texture Analyzer (Stable Micro Systems, UK) with a $25 \mathrm{~kg}$ load cell was used. Texture profile analysis (TPA) was conducted by compressing the centre of the sample slice to $40 \%$ of its original height using a cylindrical probe with a diameter of $20 \mathrm{~mm}$. The following test parameters were applied: test speed of $5 \mathrm{~mm} / \mathrm{s}$, post-test speed of $10 \mathrm{~mm} / \mathrm{s}$ and a trigger force of $0.20 \mathrm{~N}$.

\section{Determination of FODMAP content}

The determination of the FODMAP content was conducted using high-performance anionic exchange chromatography coupled with pulsed amperometric detection (HPAEC-PAD) to quantify the amounts of polyols (sorbitol and mannitol), monosaccharides (fructose in excess of glucose), disaccharides and oligosacchardides (fructans and GOS). A Dionex ICS-5000 + equipped with a SP Single Pump, an AS-AP Autosampler, a $10 \mu \mathrm{L}$ injection loop (full-loop was used for injection) and an ED Electrochemical Detector cell coupled with a gold working electrode and a PdH reference electrode were used for the HPAEC-PAD analysis. The gold carbo quad waveform was applied for the detection. Purified water (solution A), $225 \mathrm{mM} \mathrm{NaOH}$ (solution B), and $500 \mathrm{mM}$ $\mathrm{NaOAC}$ (solution C) were used as eluents. A Dionex CarboPac PA 200 analytical column $(3 \times 250 \mathrm{~nm})$ was used for the quantification of the mono-, di-, and oligosaccharides, while a Dionex CarboPac PA1 analytical column $(2 \times 250 \mathrm{~nm})$ was used for the quantification of mono-, disaccharides and polyols. Extraction of the analysed FODMAP 
components (polyols, mono-, di-, and oligosaccharides), as well as the fructan determination and the HPAEC-PAD were carried out as described by Ispiryan, et al., 2019 [30]. For the calibration two concentration ranges $(0.05-1.0 \mathrm{ppm}$ and 1.0-20.0 ppm) were used.

The total polyol content (TPC) and the total oligosaccharide content (TOC) were calculated as either the sum of sorbitol and mannitol or the sum of fructans and GOS. Excess fructose was calculated as the difference between the detected amounts of fructose and glucose. The total FODMAP content was then calculated as the content of the detected FODMAPs and a reference serve size for the bread of $55 \mathrm{~g}$ was used to ensure a comparability to the established cut-off values $(0.3 \mathrm{~g}$ per standard serve for the TOC and $0.4 \mathrm{~g}$ per standard serve for the TPC) [34]. The same serve size was used for the calculation of FODMAP contents in dough to assess the change of the FODMAP content during processing.

\section{Determination of the amount of total available carbohydrates}

The amount of total available carbohydrates (TAC) in freeze-dried samples was quantified with a total starch assay (K-TSTA, Megazyme, Ireland). Analysis was conducted as described in the manual provided by the supplier.

\section{In vitro starch digestion and release of reducing sugars}

In vitro starch digestion and the release of reducing sugars was detected based on the method described by Heitmann, et al. [35]. All bread samples were cut and subsequently blended using a lab-scale grinder (DeLonghi, Italy). A sample amount of $4 \mathrm{~g}$ was weighed and mixed with $20 \mathrm{~mL}$ of sodium-potassium phosphate buffer (0.2 M, pH 6.9). After $\mathrm{pH}$-adjustment of each suspension to 1.5 with $8 \mathrm{M} \mathrm{HCl}$, $5 \mathrm{~mL}$ of pepsin solution (EC 3.4.23.1, $526 \mathrm{U} / \mathrm{mg}$ solid, 115 $\mathrm{U} / \mathrm{mL}$ ) were added and the suspensions were incubated at $37{ }^{\circ} \mathrm{C}$ for $30 \mathrm{~min}$. Pancreatic $\alpha$-amylase (EC 3.2.1.1, 15 $\mathrm{U} / \mathrm{mg}$ solid, $110 \mathrm{U} / \mathrm{mL}$ ) in a volume of $1 \mathrm{~mL}$ was added to the suspension after the $\mathrm{pH}$ was increased to 6.9 using $6 \mathrm{~N} \mathrm{NaOH}$. The volume of the suspensions was adjusted to $50 \mathrm{~mL}$ with a sodium-potassium buffer $(0.2 \mathrm{M}, \mathrm{pH} 6.9)$ and subsequently transferred into a dialysis tubing $(25 \mathrm{~mm}$ width, length $40 \mathrm{~cm}, 14 \mathrm{kDa}$, supplied by Sigma-Aldrich) together with 6 glass beads. Each tubing was placed into a separate beaker containing $450 \mathrm{~mL}$ sodium-potassium phosphate buffer and incubations were executed at $37{ }^{\circ} \mathrm{C}$ for $4 \mathrm{~h}$. Dialysis tubes were inverted and moved every $15 \mathrm{~min}$ over the duration of the experiment. Every $30 \mathrm{~min} 1 \mathrm{~mL}$ of each dialysate was taken and replaced by an equal volume of buffer. Each sample was analysed in order to obtain the amount of reducing sugars released by the enzymatic digestion of starch. Therefore, $100 \mu \mathrm{L}$ of the dialysate were transferred into a $1.5 \mathrm{~mL}$ Eppendorf tube and $100 \mu \mathrm{L}$ of a 3,5-dinitrosalicylic acid reagent (DNS; 3,5-dinitrosalicylic acid dissolved in $2 \mathrm{M}$ sodium hydroxide and solution of potassium sodium tartrate tetrahydrate in water) were added. The sample-reagent-mixture was subsequently heated in a block heater (VWR, USA) at $100{ }^{\circ} \mathrm{C}$ for $10 \mathrm{~min}$ and immediately placed in an ice bath. Afterwards, $1 \mathrm{~mL}$ of distilled water was added, and the absorbance was measured with a spectrophotometer (Helios Gamma, Thermo Electron Co., UK) at $546 \mathrm{~nm}$. The values of the reducing sugars released (RSR) were calculated as maltose equivalents and are expressed as a percentage of the TAC.

\section{Scanning Electron Microscopy}

Images of the crumb structure were taken using Scanning Electron Microscopy (SEM). Therefore, freeze-dried crumb was mounted on stubs (G 306;10 $\mathrm{mm} \times 10 \mathrm{~mm}$ Diameter; Agar Scientific, UK) and fixated using carbon tape (G3357N; Carbon Tabs 9 mm; Agar Scientific, UK). Mounted samples were sputter coated with a gold-palladium alloy (ratio of 80/20), using a Polaron E5150 sputter coating unit, and imaging was executed with a JEOL Scanning Electron Microscope (JSM-5510, Jeol Ltd., Tokyo, Japan). The following settings were applied: $5 \mathrm{kV}$ voltage, $20 \mathrm{~mm}$ working distance and a magnification factor of 1000 .

\section{Statistical analysis}

Each measurement has been performed in a triplicate. Statistical evaluation was carried out using SPSS (Version 25). Significant differences were evaluated using both a one-way ANOVA with post-hoc Tukey test $(p \leq 0.05)$ and a two-way ANOVA followed by a post-hoc Tukey test $(p \leq 0.05)$.

\section{Results}

\section{Compositional analysis}

Moisture contents [\%] and the total FODMAP contents [g/100] oft the raw ingredients are shown in Table 2. Except for guar gum, significantly lower moisture contents were measured compared to the moisture contents determined in baker's flour and wheat bran. Both baker's flour and wheat bran have significantly higher FODMAP contents compared to the amounts detected in the other ingredients. However, wheat starch and vital gluten contained fructan and low amounts of $\alpha$-galactooligosaccharides (GOS). Therefore, total FODMAP contents of $0.56 \mathrm{~g} / 100 \mathrm{~g}$ and $0.01 \mathrm{~g} / 100 \mathrm{~g}$ were quantified in these ingredients [23]. 
Table 2 Composition of the raw materials regarding their moisture [\%], Total FODMAP content [\%] and dietary fibre content [\%]; [21]

\begin{tabular}{|c|c|c|c|c|c|c|c|c|}
\hline & Baker's Flour & Wheat Bran & Wheat Starch & Vital Gluten & Psyllium & Guar Gum & Bamboo & Cellulose \\
\hline Moisture [\%] & $12.79 \pm 0.16^{\mathrm{e}}$ & $13.33 \pm 0.03^{f}$ & $12.74 \pm 0.04^{\mathrm{e}}$ & $9.23 \pm 0.02^{c}$ & $7.66 \pm 0.01^{b}$ & $11.27 \pm 0.12^{\mathrm{d}}$ & $5.80 \pm 0.05^{\mathrm{a}}$ & $7.49 \pm 0.06^{b}$ \\
\hline $\begin{array}{l}\text { Total FOD- } \\
\text { MAP content } \\
{[\mathrm{g} / 100 \mathrm{~g}]}\end{array}$ & $1.14 \pm 0.13^{c^{* *}}$ & $3.62 \pm 0.10^{d}$ & $0.01 \pm 0.002^{a^{* *}}$ & $0.56 \pm 0.002^{b^{* *}}$ & n.d & n.d & n.d & n.d \\
\hline $\mathrm{DF}[\%]^{*}$ & 3.2 & 34.5 & n.s & n.s & 85 & 90 & 97 & 98 \\
\hline
\end{tabular}

Means \pm standard deviation with different letters in the same row were significantly different $(p \leq 0.05)$; n.d.- non determinable or concentrations underneath 0.005 [g/100 g]; n.s.- not specified

*Values given by the supplier

**Values based on studies conducted by Ispiryan, et al. 2020[23]

No FODMAPs were determined in the fibre ingredients (bamboo, cellulose, psyllium and guar gum). The contents of dietary fibre (specified by the supplier) differ largely. The lowest fibre content was specified for baker's flour with $3.2 \%$. Wheat bran possessed the second-lowest fibre content with $34.5 \%$. The low FODMAP fibre ingredients exceeded dietary fibre contents of $80 \%$.

\section{Empirical dough analysis}

\section{Farinograph}

The farinograph results revealed vast differences in the water absorption of the different dough formulations (Table 3). BFC, BFPs, LFC and the LFPs showed a water absorption between 50 and $70 \%$. The LFC and the incorporation of powdered cellulose in a concentration of $3 \mathrm{~g} / 100 \mathrm{~g}$ resulted both in the lowest amounts of water needed for adjustment (59.15\% and 59.29\%). It was also observed that wheat-based products, such as the BFC and the wheat-bran controls, resulted in a higher water absorption compared to the LFC and the LFPs enriched with both bamboo and cellulose. Only formulations fortified with $3 \mathrm{~g} / 100 \mathrm{~g}$ did not lead to an increased water absorption compared to the LFC. Recipes with a fibre concentration of $6 \mathrm{~g} / 100 \mathrm{~g}$ led to a significant increase in water absorption. The two soluble fibres psyllium and guar gum showed the overall highest values of water absorption for both concentrations since they resulted in values of water absorption above $70 \%$. Psyllium in a concentration of $6 \mathrm{~g} / 100 \mathrm{~g}$ leads to the highest increase in water absorption compared to the LFC since a value of $112.20 \pm 2.02 \%$ was determined.

\section{GlutoPeak}

The GlutoPeak results were obtained to gain an understanding of the effect different fibres have on the formation of the gluten network, which is a major factor for the dough performance. An overview of the data obtained can be found in Table 3 and the obtained torque curves are presented in Fig. 1. The results obtained for the GlutoPeak measurements need to be divided into two main categories since two different amounts of water were applied. A lower ratio of solid to water (50/50) was applied to the BFC, wheat-bran products, psyllium, and guar gum formulations.

The difference between the BFC and the LFC is evident in the obtained curves (Fig. 1). It was observed that BFC reached a peak maximum above $100 \mathrm{BE}$ after $23 \mathrm{~s}$, while for LFC a higher PMT of $121.50 \pm 0.71 \mathrm{~s}$ and a lower MT of $53.50 \pm 0.71 \mathrm{BE}$ was observed. The MT values for both concentrations of psyllium and guar gum have been observed to be the highest values overall. However, significant differences between the $3 \mathrm{~g} / 100 \mathrm{~g}$ formulations and the $6 \mathrm{~g} / 100 \mathrm{~g}$ formulations in the MT and an increase of those values were found for both psyllium and guar gum samples. Significantly shorter PMT were measured for the application of higher concentrations of psyllium and guar gum. Formulations of both ingredients with a fibre content of $6 \mathrm{~g} / 100 \mathrm{~g}$ possessed PMTs under $20 \mathrm{~s}$. All curves obtained for LFPs enriched with psyllium and guar gum in concentrations of $6 \mathrm{~g} / 100 \mathrm{~g}$ showed a steep incline in force followed by a fast decrease.

Curves for the formulations with a fibre content of $3 \mathrm{~g} / 100 \mathrm{~g}$ possessed a slow increase in torque. The MT measured for the BFC was the second highest. Only the torque curve of BFC showed a starting phase with a steep incline followed by a slow but constant increase of the torque until the MT was reached. Also, only for the BFC a slow relaxation and the development of permanent torque value were measured. Enrichment with wheat bran in both concentrations led to a decrease of the MT and a delayed PMT. A significant decrease in the MT and a significant increase in the PMT was detected for the formulations containing $6 \mathrm{~g} / 100 \mathrm{~g}$ of wheat bran compared to the lower wheat bran concentration. The measured curves for wheat bran products both revealed a slow, constant incline and no significant decline after reaching the MT. Measurements carried out with a ratio of 56/44 between solids and water were used for the low FODMAP control and the insoluble fibres (bamboo 


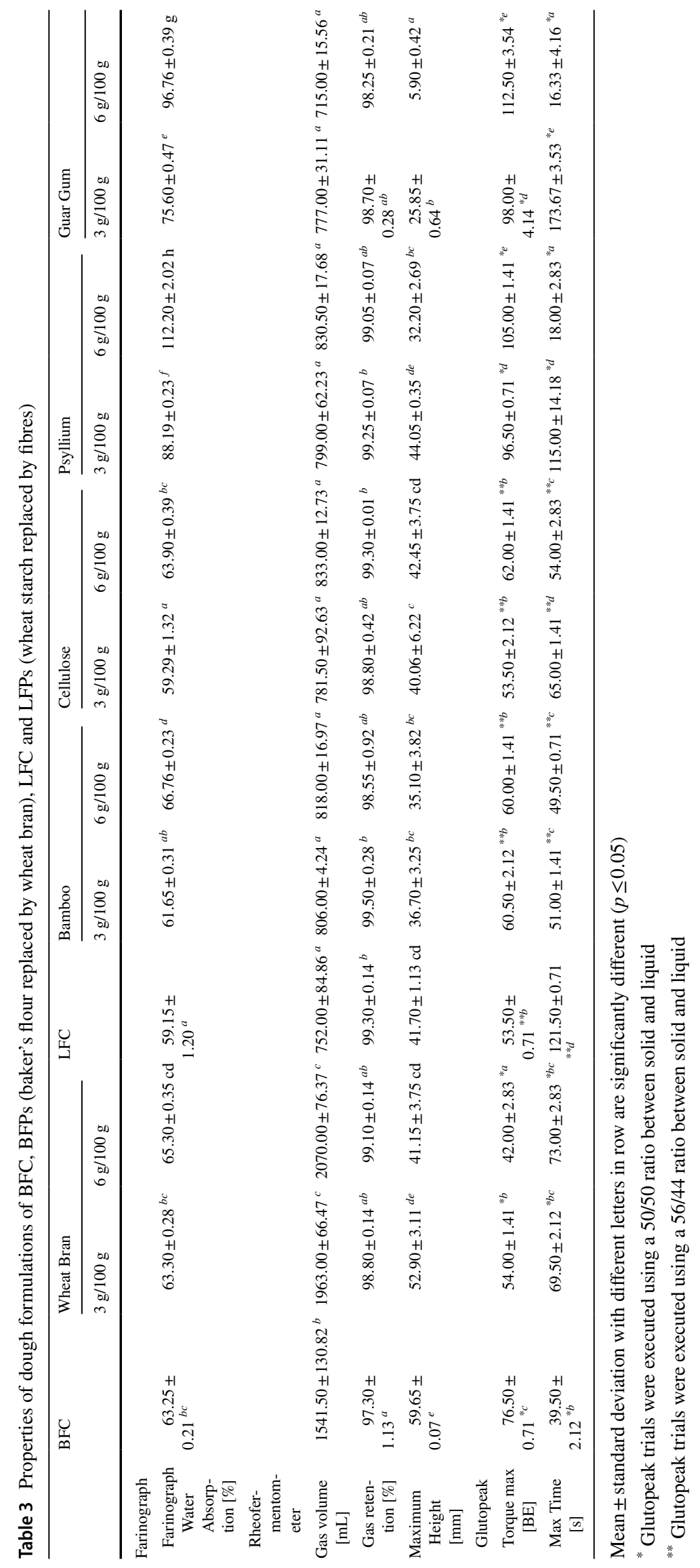


Fig. 1 Torque curves [BE] for the Glutopeak measurements of the dough formulations executed with solid-to-liquid ratios of 50/50 (a) or 56/44 (b) [a]

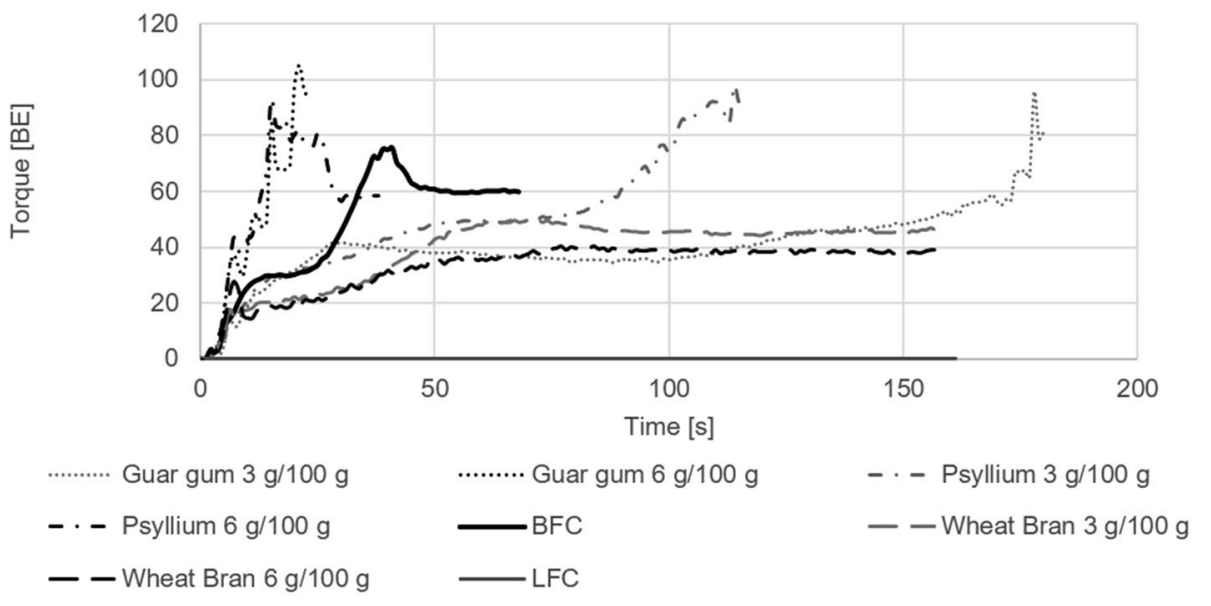

[b]

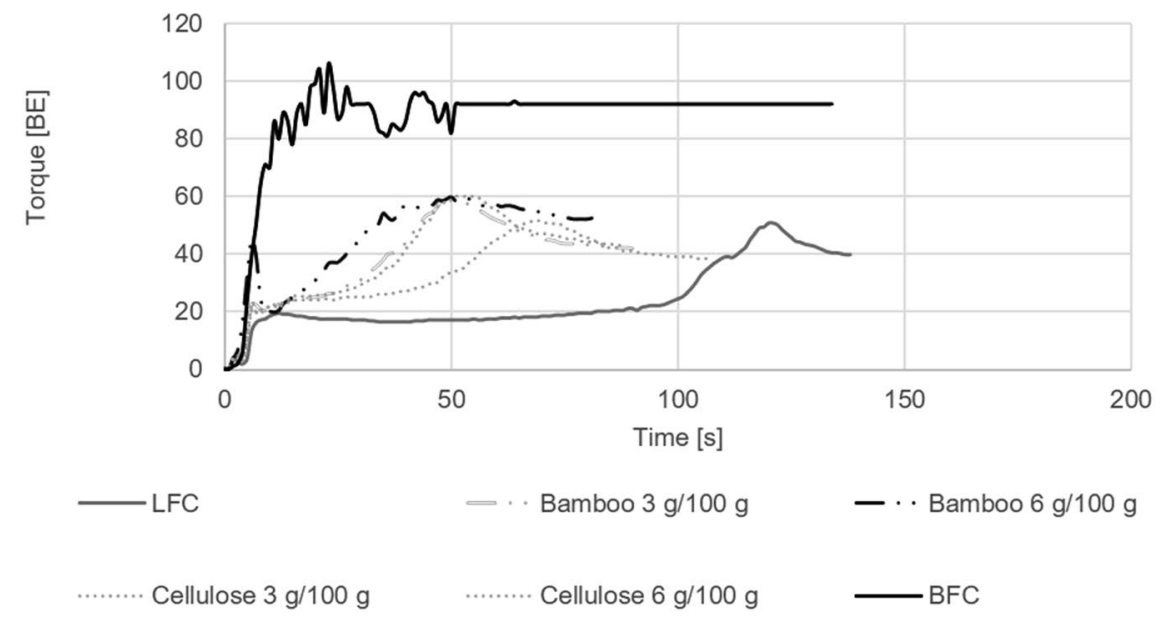

and powdered cellulose). Both insoluble fibres decreased the time to reach the maximum torque from $121.50 \mathrm{~s}$ to times under $70 \mathrm{~s}$. However, both fibres influenced the maximum torque differently. The addition of bamboo fibre in a concentration of $3 \mathrm{~g} / 100 \mathrm{~g}$ already led to a higher torque value, while cellulose only led to a rise of the torque value in a concentration of $6 \mathrm{~g} / 100 \mathrm{~g}$. Significant differences between the two different concentrations were analysed for cellulose, however, not for the use of bamboo. Torque curves of the LFPs executed at this ratio all showed an equilibration phase of $10 \mathrm{~s}$ followed by a slower increase and a slow relaxation. Curves of both fibres show a faster incline and a shorter equilibration phase than the LFC.

\section{Rheofermentometer}

For all LFPs and the LFC a total gas production beneath $900 \mathrm{~mL}$ was detected and no significant differences were found. However, the BFC and the BFPs produced significantly higher amounts of $\mathrm{CO}_{2}$ above $1500 \mathrm{~mL}$. Enrichment with wheat bran leads to a significant increase in total gas production. It was observed that the BFC caused the highest dough rise overall. However, dough rise in both BFPs and LFPs decreased after the incorporation of fibres. Products including soluble fibres (psyllium, guar gum) and wheat bran with concentrations of $6 \mathrm{~g} / 100 \mathrm{~g}$ were observed to have a significantly lower dough rise compared to the products with a lower fibre addition level. The insoluble fibres (bamboo, powdered cellulose) did not result in significant differences between the two dosages. Guar gum added in a concentration of $6 \mathrm{~g} / 100 \mathrm{~g}$ showed the overall lowest dough rise. All samples were found to retain over $90 \%$ of the $\mathrm{CO}_{2}$ generated during fermentation and only small differences were observed between all tested samples.

\section{Quality characteristics of breads}

A visual evaluation of the produced breads (Fig. 2) showed the differences in crumb structure and loaf volume caused by the addition of the various fibres. This correlates with 

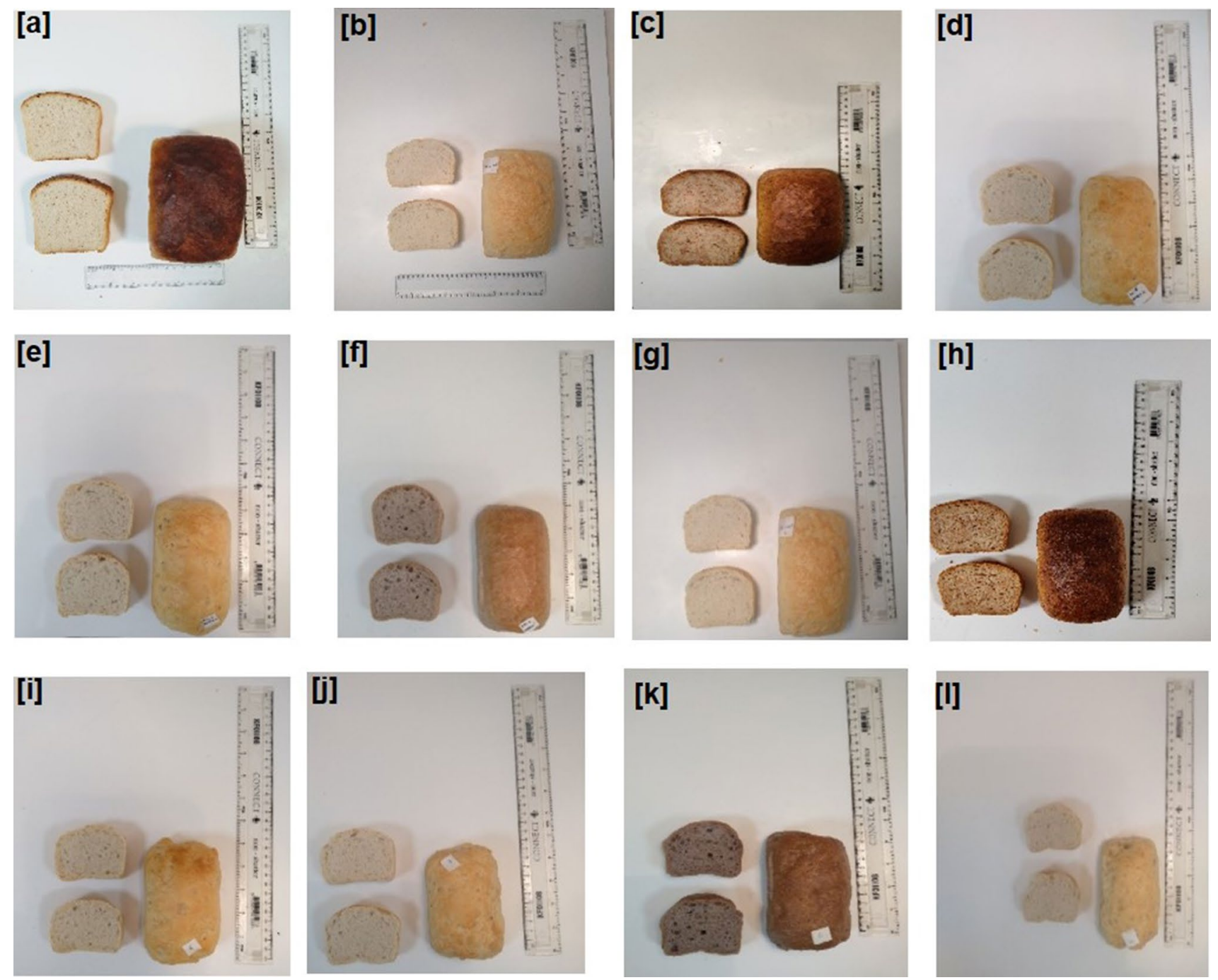

Fig. 2 Photographs of the BFC (a), LFC (b), and breads with addition of wheat bran (c), bamboo fibre (d), cellulose (e), psyllium (f) and guar gum (g) in a concentration of $3 \mathrm{~g} / 100 \mathrm{~g}$ and wheat bran (h),

the significant differences in the characteristics of the breads which were detected (Table 4). The BFC had the highest specific volume with $3.23 \pm 0.27 \mathrm{~mL} / \mathrm{g}$. The LFC showed the second-highest specific volume. The addition of the fibre ingredients caused a decrease in the specific volume depending on the used concentration in both the BFPs and the LFP. For the LFPs, psyllium caused the lowest rate of decrease in specific volume, while guar gum caused the highest decrease. Regarding the hardness of the breads an increase was observed for wheat bran compared to the BFC. Bamboo, cellulose, and guar gum resulted in an increased hardness compared to the LFC. This trend was observed for both the measurement directly after the cool-down period and after $24 \mathrm{~h}$. Psyllium was the only fibre that caused an improvement in hardness compared to the LFC in both concentrations and no significant bamboo fibre (i), cellulose (j), psyllium (k) and guar gum (l) in a concentration of $6 \mathrm{~g} / 100 \mathrm{~g}$

differences were observed for the two dosages. The cell area and the number of cells were evaluated for the investigation of the crumb structure. For the BFPs it was discovered that wheat bran decreased the number of cells and if added in a high fibre concentration it also increased the cell area. For the LFPs various effects were observed depending on the applied ingredient. Bamboo fibre and powdered cellulose showed no significant influence on the number of cells. Psyllium decreased the cell number, regardless the addition level. The incorporation of guar gum increased the number of cells only in a concentration of $3 \mathrm{~g} / 100 \mathrm{~g}$, while no differences in the cell number occurred between the addition of $6 \mathrm{~g} / 100$ of guar gum and the LFC. All fibres, except psyllium, caused a significantly lower cell area. Further increase was detected for the use of $6 \mathrm{~g} / 100 \mathrm{~g}$ of the various ingredients. Implementation of 


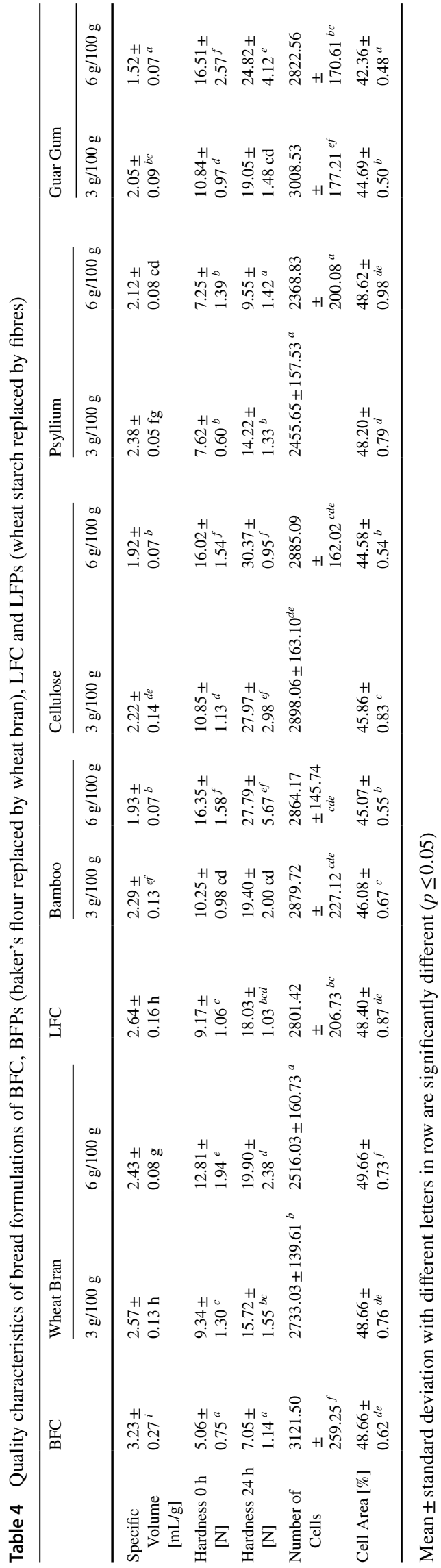
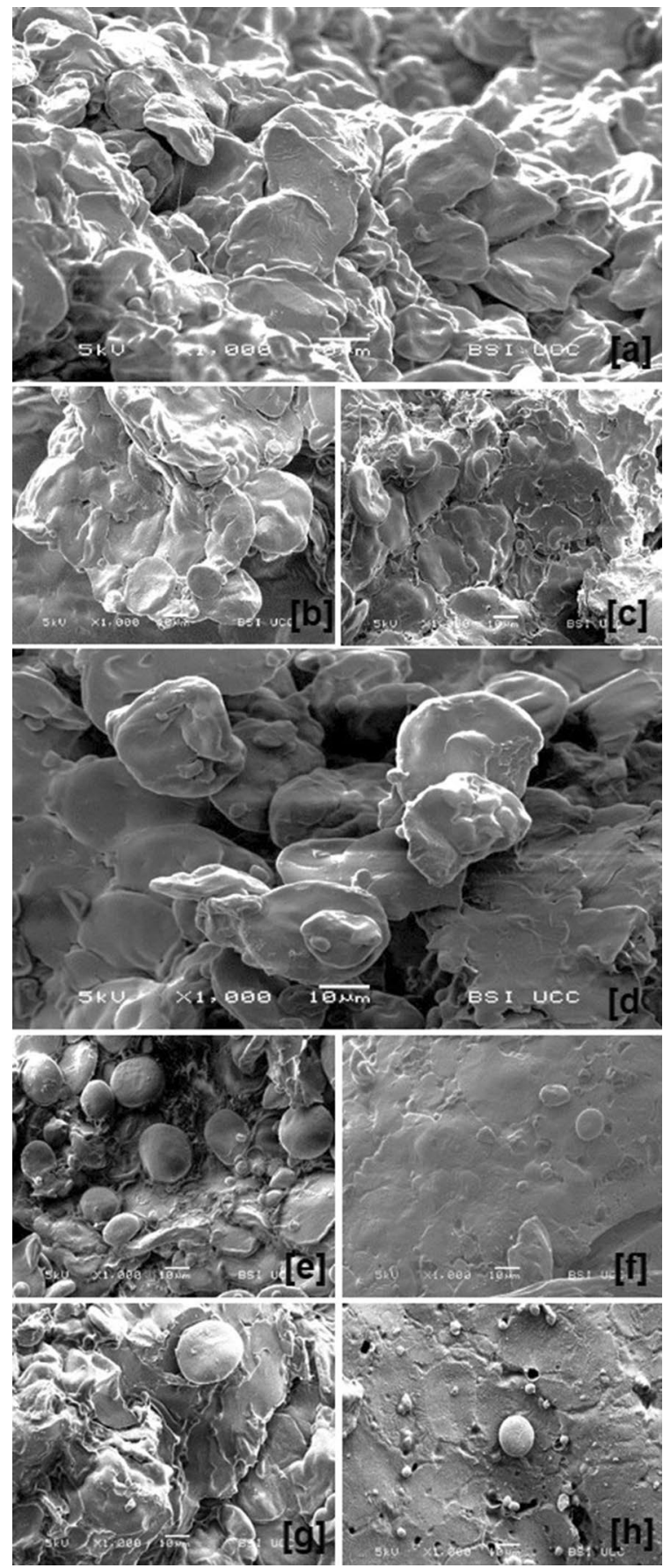

Fig. 3 SEM-Images of the crumb structure of the baker's flour control (a), breads containing $3 \mathrm{~g} / 100 \mathrm{~g}$ (b) or $6 \mathrm{~g} / 100 \mathrm{~g}$ (c) of wheat bran, low FODMAP control breads (d) breads containing $3 \mathrm{~g} / 100 \mathrm{~g}$ (e) or $6 \mathrm{~g} / 100 \mathrm{~g}$ (g) of bamboo fibre, and breads containing $3 \mathrm{~g} /$ $100 \mathrm{~g}(\mathbf{f})$ or $6 \mathrm{~g} / 100 \mathrm{~g}(\mathbf{h})$ of psyllium

psyllium resulted in no significant differences compared to the LFC and the BFC. 


\section{Scannin Electrone Microscope-imaging of bread crumb structure}

Imaging of the crumb structure was executed for all bread samples. Figure 3 depicts the SEM images of the crumb structure of the BFC, wheat bran breads, LFC, bamboo fibre breads and psyllium breads. Significant differences were observed for the various breads depending on the incorporated fibre. Breads of the low FODMAP control possess both high amounts of gelatinised and modified starch granules instead of intact and unaltered starch granules. Furthermore, the network covering the starch granules was weak. The SEM images of the BFC showed a similar crumb structure to the LFC since gelatinised starch granules were observed. In all breads with incorporated fibre an alteration of the crumb structure was discovered. Two different trends were observed for the modification of the bread system depending on the use of insoluble/moderately fermentable fibres (bamboo, powdered cellulose, wheat bran) or of soluble fibres (psyllium and guar gum). In breads enriched with $3 \mathrm{~g} / 100 \mathrm{~g}$ and $6 \mathrm{~g} / 100 \mathrm{~g}$ of bamboo fibre both not gelatinised and swollen starch granules were observed. Also, the interference of the protein network and the presence of single particles were observed. However, it was also discovered that enrichment with $6 \mathrm{~g} / 100 \mathrm{~g}$ had a lower impact on the crumb structure than the use of only $3 \mathrm{~g} / 100 \mathrm{~g}$. Breads fortified with cellulose and wheat bran (both concentrations) resulted in a similar crumb structure (Data not shown). The use of soluble fibres, such as psyllium (Fig. 3) and guar gum, led to the formation of a continuous network and a coating of the starch granules. This effect was observed for both fibre concentrations. However, damages in the network and a higher ratio of holes occurred in breads with a fibre concentration of $6 \mathrm{~g} / 100 \mathrm{~g}$.

\section{Total available carbohydrate content and in vitro starch digestibility}

The content of the TACs in breads was determined to evaluate the nutritional values of the various products. The values of the TAC are presented in Table 5. For the BFC and the BFPs no significant differences have been observed. For the LFPs a decrease of the TAC was detected. An increase in the added amount leads to a further decline of the TAC. The strongest effect of reduction of TAC was found for the incorporation of psyllium and guar gum. For the addition of bamboo and cellulose no significant differences were measured.

In vitro digestibility of the available carbohydrates and the release of sugars was used to evaluate the nutritional properties of both control breads and the fibre containing prototypes. The curves obtained for the reducing sugars released (RSR) over a time of $4 \mathrm{~h}$ are depicted in Fig. 4. The release of reducing sugars in fibre enriched breads was
Table 5 Content of TAC $[\mathrm{g} / 100 \mathrm{~g}]$ of bread formulations of BFC, BFPs (baker's flour replaced by wheat bran), LFC and LFPs (wheat starch replaced by fibres)

\begin{tabular}{|c|c|c|}
\hline & & $\begin{array}{l}\text { Total available car- } \\
\text { bohydrates }[\mathrm{g} / 100 \mathrm{~g}]\end{array}$ \\
\hline $\mathrm{BFC}$ & & $40.23 \pm 1.93 \mathrm{fg}$ \\
\hline \multirow[t]{2}{*}{ Wheat Bran } & $3 \mathrm{~g} / 100 \mathrm{~g}$ & $45.65 \pm 0.97 \mathrm{~g}$ \\
\hline & $6 \mathrm{~g} / 100 \mathrm{~g}$ & $36.25 \pm 3.91^{\mathrm{def}}$ \\
\hline LFC & & $43.99 \pm 3.76 \mathrm{~g}$ \\
\hline \multirow[t]{2}{*}{ Bamboo } & $3 \mathrm{~g} / 100 \mathrm{~g}$ & $36.89 \pm 2.08^{\mathrm{def}}$ \\
\hline & $6 \mathrm{~g} / 100 \mathrm{~g}$ & $21.59 \pm 0.80^{b c}$ \\
\hline \multirow[t]{2}{*}{ Cellulose } & $3 \mathrm{~g} / 100 \mathrm{~g}$ & $39.17 \pm 0.24^{\mathrm{efg}}$ \\
\hline & $6 \mathrm{~g} / 100 \mathrm{~g}$ & $22.50 \pm 2.77^{c}$ \\
\hline \multirow[t]{2}{*}{ Psyllium } & $3 \mathrm{~g} / 100 \mathrm{~g}$ & $32.63 \pm 0.39^{\mathrm{de}}$ \\
\hline & $6 \mathrm{~g} / 100 \mathrm{~g}$ & $12.00 \pm 0.73^{a}$ \\
\hline \multirow[t]{2}{*}{ Guar gum } & $3 \mathrm{~g} / 100 \mathrm{~g}$ & $30.42 \pm 0.96^{\mathrm{d}}$ \\
\hline & $6 \mathrm{~g} / 100 \mathrm{~g}$ & $14.66 \pm 0.37^{\mathrm{ab}}$ \\
\hline
\end{tabular}

Mean \pm standard deviation with different letters in row are significantly different $(p \leq 0.05)$

compared against either the BFC for the use of wheat bran and against the LFC for the fibre enriched prototypes. The BFC showed with $[8.84 \pm 0.38] \%$ the highest RSR value after $30 \mathrm{~min}$ and with $[38.99 \pm 4.70] \%$ also the highest value after $4 \mathrm{~h}$. In the LFC a very low initial concentration of RSR beneath $1 \%$ was detected. However, a faster increase of the amount of RSR was examined for the control based on starch and gluten, since a release of $13.42 \%$ of RSR was seen between the measurement after $30 \mathrm{~min}$ and $2 \mathrm{~h}$. However, for the BFC only an increase of $11.68 \%$ during this time was measured. For both the products with $3 \mathrm{~g} / 100 \mathrm{~g}$ of fibre [a] and the products with $6 \mathrm{~g} / 100 \mathrm{~g}$ of fibre [b], it was observed that during the digestion less reducing sugar residues were released compared to the two control products. Not only the total amount of RSR after $4 \mathrm{~h}$ was decreased, also the rate of sugar release was affected. For all fibre products, no sugar release or starch hydrolysis was detected in the first $60 \mathrm{~min}$. However, after $90 \mathrm{~min}$ an increase of sugar concentrations was determined. The RSR curves of the breads with $3 \mathrm{~g} / 100 \mathrm{~g}$ of wheat bran or psyllium showed the slowest sugar release and the lowest overall RSR values, while guar gum showed the least impaired increase of reducing sugars among the products with $3 \mathrm{~g} / 100 \mathrm{~g}$ of fibre. The higher fibre concentration resulted in a further decrease of the starch digestion, since only RSR values below $20 \%$ were determined. However, variations were seen in the velocity of the digestion and the final amount of RSR detected. It was observed that an increase in psyllium and wheat bran had the lowest impact since the smallest differences were determined 
Fig. 4 In vitro release of reducing sugars (RSR) based on total available carbohydrates (TAC) over time for breads with $3 \mathrm{~g} / 100 \mathrm{~g}$ of fibre (a) and breads with $6 \mathrm{~g} / 100 \mathrm{~g}$ of fibre (b)
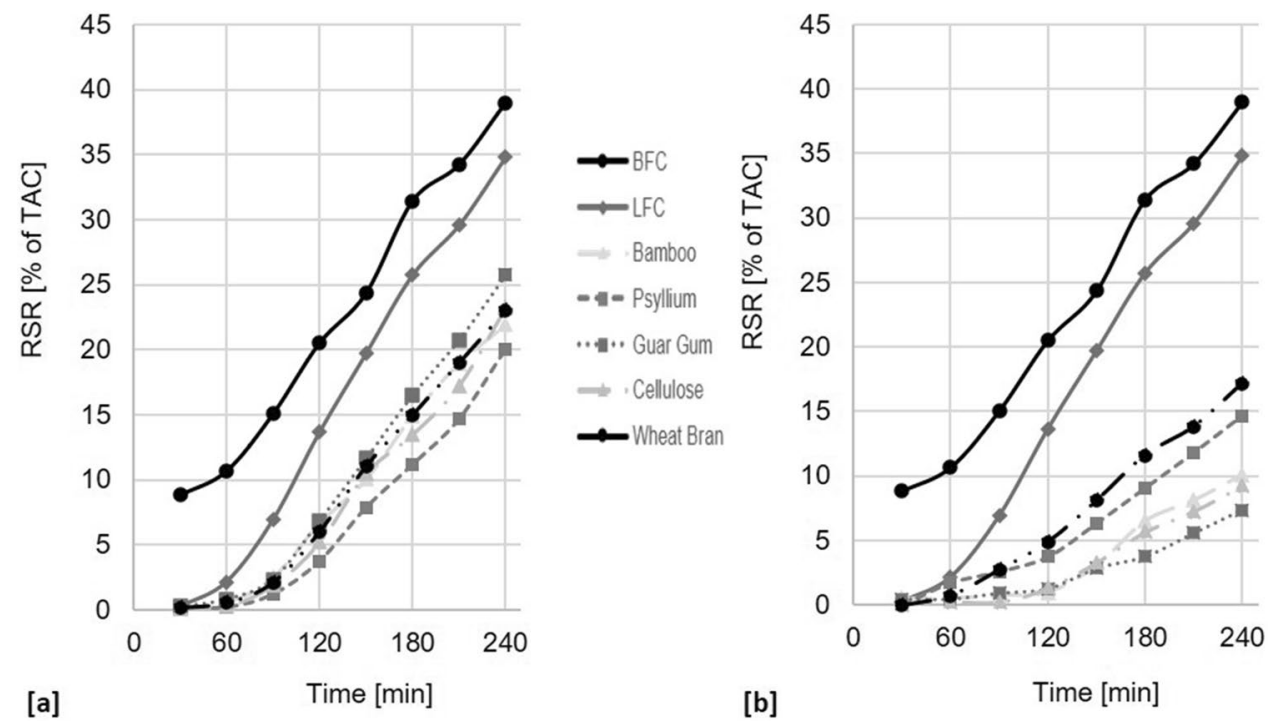

between the $3 \mathrm{~g} / 100 \mathrm{~g}$ and the $6 \mathrm{~g} / 100 \mathrm{~g}$ products of these fibres. The highest difference between the two concentrations was observed for guar gum, which had the slowest release of sugars and the overall lowest RSR value among the products with a fibre content of $6 \mathrm{~g} / 100 \mathrm{~g}$.

\section{Content of fermentable oligo-, di-, monosaccharides and polyols}

The FODMAP content of the breads before proofing and after baking are shown in Fig. 5. In both dough and bread of all samples, FODMAPs were quantified and only two groups of FODMAPs, polyols (mentioned as TPC in the methods section) and oligosaccharides (in the form of fructans and GOS; mentioned as TOC in the methods section), were identified to be present in all samples. However, the total oligosaccharide content exceeds the amount of polyols in all products (Data not shown).

Total FODMAP contents in all low FODMAP products were significantly lower than the values measured for the products based on baker's flour. It was also observed that the incorporation of fibres in a concentration of $6 \mathrm{~g} / 100 \mathrm{~g}$
Fig. 5 FODMAP content $[\mathrm{g} / 55 \mathrm{~g}]$ of doughs and breads with $3 \mathrm{~g} / 100 \mathrm{~g}$ (a)and $6 \mathrm{~g} /$ $100 \mathrm{~g}(\mathbf{b})$ of fibre; all values with different letters are significantly different $(p \leq 0.05)$ [a]

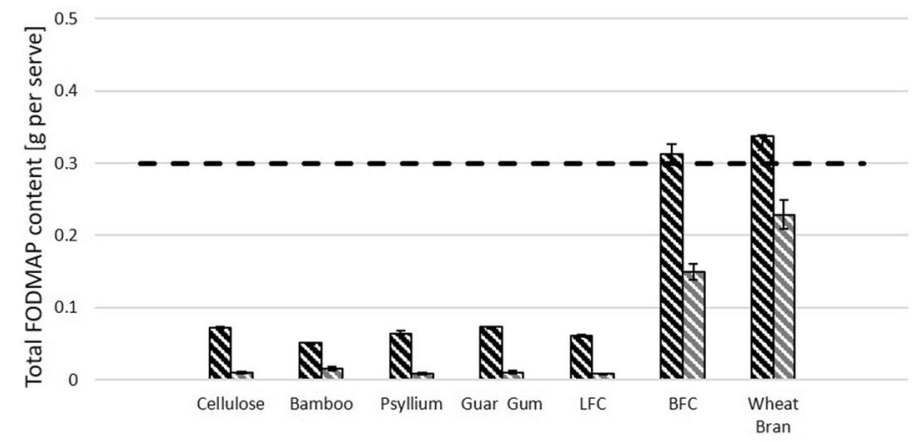

[b]

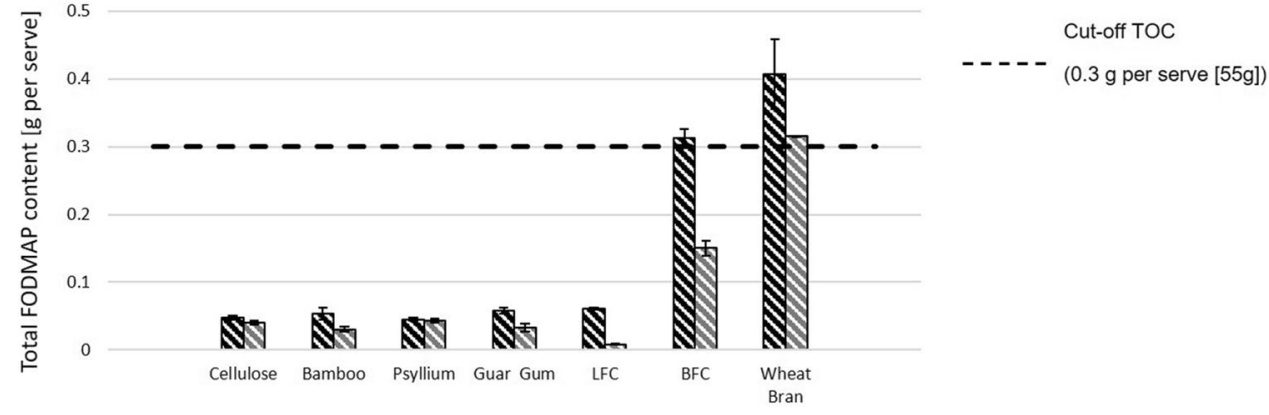


led to lower concentrations of FODMAPs in LFPs. The total FODMAP content of all prototypes is beneath both the cutoff value for oligosaccharides and polyols.

Baker's flour-based products showed the highest total FODMAP content in both the doughs before proofing and in the final breads. The total FODMAP content measured in the dough of the BFC and doughs with both concentrations of wheat bran exceeded the cut-off limit of the TOC of $0.3 \mathrm{~g}$ per standard serve ( $55 \mathrm{~g}$ of bread). Enrichment with wheat bran resulted in an increase of the total FODMAP content in breads. However, only a concentration of $6 \mathrm{~g} / 100 \mathrm{~g}$ lead to a significantly higher total FODMAP content in the analysed dough. Only in wheat bran products total FODMAP contents were detected, which were equal to the cut-off limit or even exceeded it. However, a significant reduction of the total FODMAP content during the baking process was examined for all BFPs and LFPS with a fibre concentration of $3 \mathrm{~g} / 100 \mathrm{~g}$.

\section{Discussion}

\section{Dough and bread properties}

The assessment of both the dough and bread properties revealed a major dependency on the solubility, viscosity, and water-binding capacities of the various fibres.. The water absorption results obtained with the Farinograph are the most prominent indicator for this. The observed rise of the water absorption after the addition of fibres is a wellreported phenomenon. Several factors are hypothesised to be responsible for the higher water absorptions caused by fibre enrichment. Studies conducted by Rosel, et al. and Noort et al. $[36,37]$ investigated the correlation between the water absorption of fibres and the water absorption of doughs. No direct link between those two parameters could be established. However, a connection seems present in this study, since both guar gum and psyllium were the only ingredients that caused a water absorption above $70 \%$ in concentrations of $3 \mathrm{~g} / 100 \mathrm{~g}$. Both fibres possessed the highest water-binding capacities $\left(20 \mathrm{~g} \mathrm{H} 2 \mathrm{O} / \mathrm{g}\right.$ and $\left.21.05 \mathrm{~g} \mathrm{H}_{2} \mathrm{O} / \mathrm{g}\right)$, which were specified by the supplier or reported in the literature [38]. The higher water-binding capacity of these two fibres can be linked to their ability to form gel-networks and therefore increase the dough viscosity. The rise in the water absorption by cellulose, bamboo fibre and wheat bran is hypothesised to be caused by a higher amount of interactions between water and the hydroxyl groups of the fibres [20,37]. Wheat bran consists of several fibres, such as arabinoxylans and other pentosans, which also react like bamboo or cellulos $[27,39,40]$. Furthermore, the gluten network itself has a major impact on the water absorption of the dough and a stable gluten network can result in a higher water absorption
[36]. However, in this study it was found that the gluten network is largely influenced by the before-mentioned characteristics of the fibres, as the GlutoPeak-results suggest. The development of the gluten network was found to be largely dependent on two factors: the use of either baker's flour or the starch-gluten blend for bread preparation, and the type of fibre which is applied. Differences in the development of a gluten network can already be seen between the control based on baker's flour and the one based on starch and vital gluten, which highlights the discrepancies stemming from the tested system itself. This is indicated by the fact that different solid/water ratios needed to be used for the Glutopeak measurements and by the fact that no gluten development for the LFC was found at a ratio of 50/50, which already suggests a weaker gluten system in the products based on wheat starch and vital gluten. The development of a weaker gluten network in the LFC can be related to a non-homogenous particle distribution in the system, since the formulations were prepared by blending ingredients varying vastly in particle size (Data not shown). It can be hypothesised that a homogenous particle distribution in the BFC, especially regarding glutenin and gliadin, caused a stronger gluten aggregation. Those differences regarding the quality of the gluten network can be used as an explanation for the generally lower specific volume of the breads and the higher increase in hardness after $24 \mathrm{~h}$ discovered in the majority of the LFPs. The gluten network and those properties are often connected with the gas retention and the water holding capacity of the bread system [41]. The weakened gluten network is a general disadvantage of the LFPs and, therefore, an inferior quality of these products can be assumed.

The importance of the applied fibre type can be seen in the vast variety of effects which were observed in this study. Two main effects were observed: the weakening of the gluten network and the enhancement of the gluten network. The impairment of the gluten aggregation due to wheat bran incorporation is caused by several factors, such as the interaction of the dietary fibre components contained in wheat bran with the water of the dough system and the interference of acids and reducing compounds, such as ferulic acid, phytate and glutathione [37, 42]. Another reason for the decrease in gluten quality due to the application of wheat bran could be the decrease replacement of baker's flour. For the LFPs the effects can be separated regarding the solubility and the viscosity of the fibre. The ability of gel formation and its connection with the water-binding capacity are reported for both psyllium and guar gum [43-47]. Gel formation and the binding of water by those fibres could result in a higher viscosity and therefore, lead to higher shear forces. These effects would furthermore explain the higher MTs and the lower PMTs determined for the use of higher concentrations. Despite the rise of the MT, the formation of a stronger gluten-network is unlikely, since a high PMT and 
a steep decline of the curves were discovered for formulations with a lower fibre amount. The weakening of the gluten network due to psyllium and guar gum could be caused by the water-binding effect of those fibres, which leads to a competition between the fibres and gluten for water [48]. An impaired gluten network and the high shear forces needed for mixing are limiting factors for the application of psyllium and guar gum into a bread system.

Bamboo and cellulose, which are both insoluble fibres led to a strengthened gluten network and an accelerated gluten aggregation since earlier PMTs were observed for all formulations of those two ingredients. The decrease of lift-off time and PMT has been reported for the use of cellulose in different particle sizes [20]. The strengthening effect might be linked to a better distribution of water in the dough system due to enhanced interactions between water and the dough system. Therefore, those fibres function as an additional plasticiser which enables faster interactions between glutenin and gliadin [20]. Varying behaviour regarding the MT values suggests differences in the interactions between the fibre molecules and the protein structure of gluten. A possible cause for those discrepancies could be an enhanced interaction between hydroxyl groups of cellulose and glutenin and gliadin, which would not only enhance the kinetic interaction between the macromolecular parts of the gluten network, but also the strength of the network. A support of this theory is that dietary fibre components in bamboo are celluloses and hemicelluloses, which would interact in a similar way to cellulose [49]. Therefore, the addition of insoluble fibres could be discussed as a method to improve the inferior gluten structure of low FODMAP model systems.

The development of the gluten network is often also associated with an influence on another important parameter for the evaluation of the dough performance, the dough rise caused by yeast fermentation [41]. In general, a significantly lower dough rise, and a lower gas production have been found for all low FODMAP products. These discrepancies between the LFPs and the BFPs were also found for the specific volume of the products. Besides gluten development, this parameter is mainly influenced by the amount of carbohydrates fermentable by yeast. Fermentable carbohydrates naturally occurring in wheat-based products include higher amounts of glucose, sucrose, fructose and minor amounts of fructans, which belong to the FODMAP group [23, 50, 51]. This is supported by the difference in the amounts of fructans determined in the BFPs and the decrease of the total FODMAP content during the baking. The absence of further fermentable carbohydrates and a very similar carbohydrate profile can be responsible for no significant differences observed between the various LFPs. However, the obtained results also suggest that beside the gas production various other factors influence which effects fibres would have on the dough rise. This is especially evident in the fact that the gas retention showed just a few significant differences, whilst significant differences were found for the maximum heights of the doughs. Despite no determination of significant differences, in each sample variances of the total gas production itself were measured and therefore a higher range of the total gas production was observed for the LFPs and the LFC. A reason for this effect might be the formation of a less extensible and less elastic crumb network, which would lead to a compression of gas and a lower maximum height and loaf volume despite no significant differences in the gas retention. Those differences in the structure can be caused by either interference with the gluten network as described earlier and a possible increase in viscosity as discussed for the incorporation of psyllium and guar gum [44, 47, 52]. The lower dough rise, which was observed for the incorporation of every fibre ingredient and the lower total gas production observed in the LFP and the LFC points out the technological limitations of those prototypes independent from the enrichment with fibre.

The analysis of the bread quality also showed a difference between the BFC and the LFC. Trends seen for the BFC are often related to a good bread quality and are in this study used as a standard since this is an example for a frequently produced bread. A correlation between the maximum height of the dough and the specific volume $(r=0.832 ; p<0.01)$ were found and therefore the initial discrepancies in the loaf volume between these two systems can be associated with the variances in the dough rise. This connection is also reported in the literature, as well as the link between the quality of the gluten network and the bread properties, such as hardness and the loaf volume [53, 54].

Despite these discrepancies, fibre incorporation caused a decline of quality in both systems for at least one of the measured parameters. The trend of a lowered specific volume, a rise in hardness and an enhanced staling, which is suggested by the results for the hardness after $24 \mathrm{~h}$, are reported for the use of various fibres in a wheat bread system [55]. The decline in quality is often related to a weakened gluten network, since this can cause a decline in dough rise, and in the water holding capacity of the bread crumb. Although, in this study it was not found that all fibres weaken the gluten network. Therefore, those negative effects seem to be rather caused by an interaction between fibres and starch and the alteration of the crumb structure, which are also dependent on the type of fibre used for the LFPs. Both the decrease of the loaf volume and the rise in hardness can be linked to the crumb structure. The specific volume and the cell area showed a positive correlation $(r=0.771, p<0.01)$ while the specific volume and the cell number showed no significant correlation. This shows that the volume of the breads is more influenced by the cell size and the stability of the cells rather than the number of cells alone. The increase in the 
cell area might be caused by more stable gas cells and a more elastic network [56]. For the BFC this is caused by the absence of interference from fibres. Psyllium might stabilise the cells by forming a gel, which is still elastic. This is supported by the fact that psyllium is a fibre which induces gel formation and the observation of a network via SEM. Psyllium was the only fibre which softened the crumb structure. Enrichment with psyllium led to an increase of the cell area and a decrease in the cell number, which both can cause a lower hardness since the amount of cell walls is decreased [57]. The effect of psyllium on hardness and the staling can also be related to its waterbinding capacity, which results in a higher water retention and prevents starch re-crystallisation, which is often referred to as the main cause of staling [58]. This theory is also supported by the fact that bamboo and cellulose resulted in the highest hardness and possessed lower water binding capacities than psyllium and guar gum. The negative effects observed for guar gum can be caused by the discrepancies in the cell area and the dough rise. Differences could be caused by a higher viscosity of guar gum, which would lead to a more tense network and therefore to smaller cells [59].

Interaction with the starch could also be an explanation for the higher hardness after $24 \mathrm{~h}$ measured for wheat bran, bamboo, and cellulose. For those fibres, a higher rate of exposed starch granules compared to the soluble fibres and the two control systems was observed during SEM. The increased accessibility of starch granules could lead to both an accelerated starch re-crystallisation and an impaired retention of water. This variety in the mechanism of the interaction between fibre and starch shows the importance of the differentiation between soluble and insoluble fibres and how valuable the characterisation of fibre ingredients is.

\section{Total Content of fermentable oligo-, di-, monosaccharides and polyols}

The small amounts of fructan and polyols found in the LFC and the LFPs mainly originate from the base ingredients (vital gluten and wheat starch). The BFC and the BFPs which were used as negative controls regarding the FODMAP content resulted in significantly higher FODMAP contents, especially for the amount of oligosaccharides. This is caused by the amount of fructans, which are oligosaccharides commonly found in cereals, such as wheat [50]. Therefore, the BFC and wheat bran contain higher FODMAP amounts. Fructans are usually stored in the husk of cereals [60]. This explains the higher fructan and total FODMAP content found for wheat bran as an ingredient. Breads enriched with wheat bran cause a higher risk of triggering symptoms in IBS patients. This fact supports the benefit of LFPs with alternative fibre sources since common cerealbased fibre ingredients cannot be used. The decrease of the fructan and GOS content in both the BFPs and LFPs during fermentation was discovered. This decline is caused by the fermentation of oligosaccharides by yeast and has been described in literature before [27, 61].

\section{Nutritional properties}

Beside the before mentioned impact on physico-chemical and technological properties, the influence on the nutritional properties needs to be discussed. The parameters that can be used to evaluate the effect on the nutritional value of breads are the in vitro starch digestibility and the release of reducing sugars, such as maltose and glucose. The digestibility of the contained available carbohydrates and the speed at which the sugars are released directly influence the blood sugar and therefore the GI. A low GI and a slow increase of blood sugar are often considered as beneficial attributes of a food product and fortification with fibres is often used to develop products with a low GI [62]. For this study, the amount of reducing sugars released by the enzymatic digestion of starch and maltodextrins via $\alpha$-amylase was used. This simulates the mechanism of carbohydrate digestion in the human gut and can therefore be used as an indicator for either positive or negative influence of food products on blood sugar. However, these measurements can only be used for the prediction of their impact on the nutritional value of food products. Cereal based products are commonly associated with a high level of starch and a fast release of glucose and maltose, which leads to the measurement of high GI values [63]. These trends were examined for both the BFC and the LFC since the fastest release and the overall highest content of reducing sugars were determined for those two product types. Therefore, these breads could result in a fast and unhindered increase of blood sugar. Despite the overall similarities between the controls regarding the in vitro sugar release smaller differences were found. The initial amount of RSR was the highest in BFC, which is caused by the higher presence of glucose and maltose originating from the baker's flour (data not shown). The faster increase in RSR which, was analysed in the LFCs might be caused by a higher accessibility of the starch granules compared to the BFC. The fibres which are naturally present in wheat, such as arabinoxylans and pentosans, could cause this slight decrease in the speed of the digestion. However, the SEM-imaging did not show differences regarding the gelatinisation of starch granules. The fortification with all the fibre ingredients led to a slower increase in RSR and therefore to an inhibition of starch hydrolysis. This impact on the sugar release and starch digestion due to fibres is frequently reported for breads and other cereal-based products, such as pasta [64]. The decrease 
in the GI reported in the literature and the decrease in the amount of RSR cannot solely be explained with discrepancies in the amount of available carbohydrates. This is especially evident for the breads based on baker's flour since no significant differences in the TAC content of the BFC and the breads enriched with wheat bran were found. Soluble fibres, such as arabinoxylans, are components found in wheat bran and their presence is causing the observed effect $[16,65]$. Those compounds can hinder the enzyme-starch interaction and can also decrease the number of gelatinised starch granules $[16,66]$. For the LFC and the fibre enriched LFPs, the replacement and dilution of starch is one factor influencing the in vitro sugar release since significant differences in the TAC have been found for the LFC and the LFPs. However, further mechanisms in which the GI is lowered need to be discussed, since the incorporation of bamboo, guar gum and psyllium in smaller quantities resulted in different shaped curves despite the fact that no significant differences in the content of total available carbohydrates were discovered. Furthermore, the differences in the purity of the ingredients and therefore variances in the amount of starch-which was replaced-are lower than the differences measured for the TAC. A factor that is supposed to have a major impact on the digestibility and the hydrolysis is the viscosity and the ability to form gels [67]. Gel forming influences the effectivity of $\alpha$-amylase by forming a network protecting starch granules from enzyme penetration [68]. This is supported by the continuous network, which was discovered during the SEM imaging. Furthermore, the influence of the viscosity would also explain the different trend observed for the insoluble and soluble fibres. The reduction of the starch digestibility and therefore the release of sugars can also be explained by the interaction between starch with water and the influence of fibres on these interactions. This effect can be applied to both fibre types. The competition of soluble fibres, as well as the interaction of insoluble fibres with starch can lower the rate of gelatinised starch, which was discovered to be crucial for the enzymatic hydrolysis [69]. A higher rate of un-swollen granules was observed during SEM for bamboo and cellulose prototypes in both concentrations and supports the before mentioned theory. For psyllium and guar gum no starch granules were observed, due to the formation of a continuous network. Another theory explaining a lowered increase of reducing sugars is the delayed sugar diffusion caused by an increase in viscosity $[63,70]$. This effect would only occur if gel-forming fibres like psyllium and guar gum are used. The efficiency of the viscous fibres psyllium and guar gum aligns with other in vivo studies, which investigated those fibres and the influence of solubility and gel formation [11, 71, 72]. These results of the in vitro sugar release highlighted both a beneficial impact of the application of fibre in both systems, as well as a dependency of the lowering rate on the solubility of the fibres, especially for the LFPs. However, the use of these isolated and purified fibre ingredients possesses one disadvantage that needs to be discussed. Due to their purification they can only be used for increasing the intake of DF and not for the simultaneous increase of other nutrients, such as minerals, vitamins and vitamin precursors including tocopherol, and antioxidants, such as ferulic acid and phenols [39]. Complex fibre ingredients, such as wheat bran, are also rich in these compounds and are therefore contributing to the daily intake of nutrients. Therefore, the addition of other micro and macronutrients should be considered when using DF ingredients with a high purity.

\section{Conclusion}

This study revealed the advantages and disadvantages of the development of a bread based on ingredients low in FODMAPS and the incorporation of fibres, which do not fall under the FODMAP criteria. Also, the comparison of these products with flour-based breads allowed the evaluation of the performance of the prototypes, as well as the identification of general limitations for fibre enrichment. The disadvantages of both the LFC and the fibre enriched prototypes were mainly affecting the technological properties of both dough and bread, such as gluten development, specific volume, and hardness after both $0 \mathrm{~h}$ and $24 \mathrm{~h}$. This shows that the application of fibres might result in a lower product quality and lower consumer acceptance compared to a commercial wheat bread. However, compared with products fortified with wheat bran, an acceptable performance of the LFPs can be considered. Beside the disadvantages and limitations, this study also revealed beneficial attributes and fibre characteristics, which can be related to a positive impact on the technological and nutritional properties of the breads. All LFP fulfil the low FODMAP criteria, since FODMAP levels were significantly lower than the cut-off values for the TOC ( $0.3 \mathrm{~g}$ per serve) or the TPC ( $0.4 \mathrm{~g}$ per serve) [34]. This shows that the approach of a reversely engineered flour could be also used for cereal-based products which do not include a processing step which lowers the FODMAP content, such as yeast or sourdough fermentation. This independency of methods to lower amounts of oligosaccharides belonging to the group of FODMAPs is also an advantage since the fructan decrease during fermentation can also lead to a decrease in the content of DF. The fibres used for this study are not reported to be digested by yeast and therefore possess a higher possibility to reach the source of fibre and high in fibre claims in the end products. These results highlight the differences of those fibres and can therefore be used for the development of products and process parameters to ensure product quality and an acceptance of fibre enriched low FODMAP breads. However, further in vivo studies need 
to be executed to proof the potential of increasing the fibre intake in IBS patients via enrichment with the investigated fibres. The most important finding in this study was the high impact of the solubility of the fibre on the quality of the dough and the bread, and the dependency on the used concentration, since this provides the possibility to predict the effect of the applied fibre. The solubility can positively impact the specific volume and the staling if applied in a concentration of $3 \mathrm{~g} / 100 \mathrm{~g}$, however, applied in a higher concentration a negative effect was observed. Insoluble fibres were observed to have a positive effect on the gluten aggregation. Overall, this study highlighted the possibility of insoluble fibres for improving the dough handling. Soluble fibres, such as psyllium, offer the highest potential regarding both the technological and nutritional quality of breads if used for the development of products aiming at the source of fibre claim.

Acknowledgements This work was funded by the Irish Department of Agriculture, Food and the Marine. Project Acronym: TALENTFOOD - Project: code 15F602. We would like to thank Tom Hannon for technical support. The authors also want to thank Stefano Rizzolini for its help with the execution of trials. Furthermore, we want to express our thanks to Lilit Ispiryan and Andrea Hoehnel for their advice and helpful discussions.

Author contributions JJA: Conceptualization; Methodology; Investigation; Writing- Original Draft; AWS: Writing- Review \& Editing; Supervision; Visualisation; EG: Writing- Review \& Editing; Supervision; Visualisation; Project administration; Funding acquisition; EZ: Writing- Review \& Editing; Supervision; Visualisation; Project administration; Funding acquisition; EKA: Writing- Review \& Editing; Supervision; Visualisation; Project administration; Funding acquisition.

Funding Open Access funding provided by the IReL Consortium. This work was funded by the Irish Department of Agriculture, Food and the Marine. Project Acronym: TALENTFOOD-Project: code 15F602.

\section{Declarations}

Conflict of interest There are no conflicts of interest or competing interests to disclose.

Ethics approval The study did not include trials with humans or animals.

Compliance with ethics requirements This article does not contain any studies with human or animal subjects.

Open Access This article is licensed under a Creative Commons Attribution 4.0 International License, which permits use, sharing, adaptation, distribution and reproduction in any medium or format, as long as you give appropriate credit to the original author(s) and the source, provide a link to the Creative Commons licence, and indicate if changes were made. The images or other third party material in this article are included in the article's Creative Commons licence, unless indicated otherwise in a credit line to the material. If material is not included in the article's Creative Commons licence and your intended use is not permitted by statutory regulation or exceeds the permitted use, you will need to obtain permission directly from the copyright holder. To view a copy of this licence, visit http://creativecommons.org/licenses/by/4.0/.

\section{References}

1. Sperber AD, Dumitrascu D, Fukudo S et al (2017) The global prevalence of IBS in adults remains elusive due to the heterogeneity of studies: a Rome Foundation working team literature review. Gut 66:1075-1082. https://doi.org/10.1136/gutjnl-2015-311240

2. Lovell RM, Ford AC (2012) Global prevalence of and risk factors for irritable bowel syndrome: a meta-analysis. Clin Gastroenterol Hepatol 10:712-721.e4. https://doi.org/10.1016/J.CGH.2012.02. 029

3. de Roest RH, Dobbs BR, Chapman BA et al (2013) The low FODMAP diet improves gastrointestinal symptoms in patients with irritable bowel syndrome: a prospective study. Int J Clin Pract 67:895-903. https://doi.org/10.1111/ijcp.12128

4. Hunt R, Fedorak R, Frohlich J et al (1993) Therapeutic role of dietary fibre. Can Fam Phys 39(897-900):903

5. Soncini M, Stasi C, Usai Satta $P$ et al (2019) IBS clinical management in Italy: the AIGO survey. Dig Liver Dis 51:782-789. https://doi.org/10.1016/j.dld.2018.10.006

6. Lacy BE, Mearin F, Chang L et al (2016) Bowel disorders. Gastroenterology 150:1393-1407.e5. https://doi.org/10.1053/j. gastro.2016.02.031

7. Bijkerk CJ, Muris JWM, Knottnerus JA et al (2004) Systematic review: the role of different types of fibre in the treatment of irritable bowel syndrome. Aliment Pharmacol Ther 19:245-251. https://doi.org/10.1111/j.0269-2813.2004.01862.x

8. European Food Safety Authority (2010) Scientific Opinion on Dietary Reference Values for carbohydrates and dietary fibre. EFSA J 8:1462. https://doi.org/10.2903/j.efsa.2010.1462.Avail able

9. Murphy N, Norat T, Ferrari P et al (2012) Dietary Fibre Intake and Risks of Cancers of the Colon and Rectum in the European Prospective Investigation into Cancer and Nutrition (EPIC). PLoS ONE 7:e39361. https://doi.org/10.1371/journal.pone. 0039361

10. Bingham SA, Day NE, Luben R et al (2003) Dietary fibre in food and protection against colorectal cancer in the European Prospective Investigation into Cancer and Nutrition (EPIC): an observational study. Lancet 361:1496-1501. https://doi.org/10.1016/ S0140-6736(03)13174-1

11. Zacherl C, Eisner P, Engel K-H (2011) In vitro model to correlate viscosity and bile acid-binding capacity of digested water-soluble and insoluble dietary fibres. Food Chem 126:423-428. https://doi. org/10.1016/J.FOODCHEM.2010.10.113

12. Dilis V, Trichopoulou A (2009) Nutritional and health properties of pulses. Med J Nutr Metab 1:149-157. https://doi.org/10.1007/ s12349-008-0023-2

13. Chouinard LE (2011) the role of psyllium fibre supplementation. In treating irritable bowel syndrome. Can J Diet Pract Res 72:e107-e114. https://doi.org/10.3148/72.1.2011.48

14. Peressini D, Sensidoni A (2009) Effect of soluble dietary fibre addition on rheological and breadmaking properties of wheat doughs. J Cereal Sci. https://doi.org/10.1016/j.jcs.2008.09.007

15. Tomlin J, Read NW (1988) The relation between bacterial degradation of viscous polysaccharides and stool output in human beings. Br J Nutr 60:467-475. https://doi.org/10.1079/BJN19 880119 
16. Foschia M, Peressini D, Sensidoni A, Brennan CS (2013) The effects of dietary fibre addition on the quality of common cereal products. J Cereal Sci 58:216-227. https://doi.org/10.1016/J.JCS. 2013.05.010

17. Ribotta PD, Pérez GT, León AE, Añón MC (2004) Effect of emulsifier and guar gum on micro structural, rheological and baking performance of frozen bread dough. Food Hydrocoll 18:305-313. https://doi.org/10.1016/S0268-005X(03)00086-9

18. Lewis SJ, Heaton KW (1999) Roughage revisited (The Effect on intestinal function of inert plastic particles of different sizes and Shape). Dig Dis Sci 44:744-748. https://doi.org/10.1023/A:10266 13909403

19. Almeida EL, Chang YK, Steel CJ (2013) Dietary fibre sources in bread: influence on technological quality. LWT Food Sci Technol 50:545-553. https://doi.org/10.1016/J.LWT.2012.08.012

20. Goldstein A, Ashrafi L, Seetharaman K (2010) Effects of cellulosic fibre on physical and rheological properties of starch, gluten and wheat flour. Int J Food Sci Technol 45:1641-1646. https://doi. org/10.1111/j.1365-2621.2010.02323.x

21. Tuck CJ, Taylor KM, Gibson PR et al (2018) Increasing symptoms in irritable bowel symptoms with ingestion of galacto-oligosaccharides are mitigated by $\alpha$-galactosidase treatment. Am J Gastroenterol 113:124-134. https://doi.org/10.1038/ajg.2017.245

22. Biesiekierski JR, Rosella O, Rose R et al (2011) Quantification of fructans, galacto-oligosacharides and other short-chain carbohydrates in processed grains and cereals. J Hum Nutr Diet 24:154176. https://doi.org/10.1111/j.1365-277X.2010.01139.x

23. Ispiryan L, Zannini E, Arendt EK (2020) Characterization of the FODMAP-profile in cereal-product ingredients. J Cereal Sci 92:102916. https://doi.org/10.1016/J.JCS.2020.102916

24. Cust AE, Skilton MR, van Bakel MME et al (2009) Total dietary carbohydrate, sugar, starch and fibre intakes in the European Prospective Investigation into Cancer and Nutrition. Eur J Clin Nutr 63:S37-S60. https://doi.org/10.1038/ejen.2009.74

25. Marsh A, Eslick EM, Eslick GD (2016) Does a diet low in FODMAPs reduce symptoms associated with functional gastrointestinal disorders? A comprehensive systematic review and meta-analysis. Eur J Nutr 55:897-906. https://doi.org/10.1007/ s00394-015-0922-1

26. Loponen J, Gänzle MG (2018) Use of sourdough in low FODMAP baking. Foods 7:1-12. https://doi.org/10.3390/foods7070096

27. Struyf N, Laurent J, Verspreet J et al (2017) Saccharomyces cerevisiae and kluyveromyces marxianus cocultures allow reduction of fermentable oligo-, Di-, and monosaccharides and polyols levels in whole wheat bread. J Agric Food Chem 65:8704-8713. https://doi.org/10.1021/acs.jafc.7b02793

28. Atzler JJ, Ispiryan L, Gallagher E et al (2020) Enzymatic degradation of FODMAPS via application of $\beta$-fructofuranosidases and $\alpha$-galactosidases_a fundamental study. J Cereal Sci 95:102993. https://doi.org/10.1016/j.jcs.2020.102993

29. Commission E (2012) Commission regulation (EU) No 1047/2012. Off J Eur Union 2012:36-37

30. Ispiryan L, Heitmann M, Hoehnel A et al (2019) Optimization and Validation of an HPAEC-PAD Method for the Quantification of FODMAPs in Cereals and Cereal-Based Products. J Agric Food Chem 67:4384-4392. https://doi.org/10.1021/acs.jafc.9b00382

31. AACC Methods, 44-15.02, 1999, 3-6

32. AACC Methods, 54-21.02, 1999, 3-6

33. AACC Methods, 82-23.01, 1999, 3-6.

34. Varney J, Barrett J, Scarlata K et al (2017) FODMAPs: food composition, defining cutoff values and international application. $\mathbf{J}$ Gastroenterol Hepatol 32:53-61

35. Heitmann M, Axel C, Zannini E, Arendt EK (2017) Modulation of in vitro predicted glycaemic index of white wheat bread by different strains of Saccharomyces cerevisiae originating from various beverage applications. Eur Food Res Technol 243:1877-1886. https://doi.org/10.1007/s00217-017-2894-2

36. Rosell CM, Santos E, Collar C (2006) Mixing properties of fibreenriched wheat bread doughs: a response surface methodology study. Eur Food Res Technol 223:333-340. https://doi.org/10. 1007/s00217-005-0208-6

37. Noort MWJ, van Haaster D, Hemery Y et al (2010) The effect of particle size of wheat bran fractions on bread quality-evidence for fibre-protein interactions. J Cereal Sci 52:59-64. https://doi. org/10.1016/J.JCS.2010.03.003

38. Horstmann SW, Axel C, Arendt EK (2018) Water absorption as a prediction tool for the application of hydrocolloids in potato starch-based bread. Food Hydrocoll 81:129-138. https://doi.org/ 10.1016/J.FOODHYD.2018.02.045

39. Stevenson L, Phillips F, Osullivan K, Walton J (2012) Wheat bran: its composition and benefits to health, a European perspective. Int J Food Sci Nutr 63:1001-1013. https://doi.org/10.3109/09637486. 2012.687366

40. Lineback DR, Kakuda NS, Tsen CC (1977) Carbohydrate composition of water-soluble pentosans from different types of wheat flours. J Food Sci 42:461-467. https://doi.org/10.1111/j.13652621.1977.tb01523.x

41. Campbell GM, Martin PJ (2012) Bread aeration and dough rheology: an introduction. Breadmaking. https://doi.org/10.1533/97808 57095695.2.299

42. Campbell GM, Ross M, Motoi L (2008) Bran in bread: effects of particle size and level of wheat and oat bran on mixing, proving and baking. Bubbles Food 2:337-354. https://doi.org/10.1016/ B978-1-891127-59-5.50037-7

43. Guo Q, Cui SW, Wang Q, Christopher Young J (2008) Fractionation and physicochemical characterization of psyllium gum. Carbohydr Polym 73:35-43. https://doi.org/10.1016/J.CARBPOL. 2007.11.001

44. Raymundo A, Fradinho P, Nunes MC (2014) Effect of Psyllium fibre content on the textural and rheological characteristics of biscuit and biscuit dough. Bioact Carbohydr Diet Fibre 3:96-105. https://doi.org/10.1016/J.BCDF.2014.03.001

45. Guo Q, Cui SW, Wang Q et al (2009) Microstructure and rheological properties of psyllium polysaccharide gel. Food Hydrocoll 23:1542-1547. https://doi.org/10.1016/J.FOODHYD.2008.10.012

46. Chudzikowski RJ (1971) Guar gum and its applications-p 00043-p00060.pdf. J Soc Cosmet Chem 22:43-60

47. Rosell CM, Santos E, Collar C (2009) Physico-chemical properties of commercial fibres from different sources: a comparative approach. Food Res Int 42:176-184. https://doi.org/10.1016/J. FOODRES.2008.10.003

48. Chaplin MF (2003) Fibre and water binding. Proc Nutr Soc 62:223-227. https://doi.org/10.1079/PNS2002203

49. Wang CH, Ma YL, Zhu DY et al (2017) Physicochemical and functional properties of dietary fiber from Bamboo Shoots (Phyllostachys praecox). Emir J Food Agric 29:509-517. https://doi. org/10.9755/ejfa.2017-02-274

50. Huynh BL, Wallwork H, Stangoulis JCR, Graham RD, Willsmore KL, Olson S, Mather, DEB (2008) Quantitative trait loci for grain fructan concentration in wheat (Triticum aestivum L.). Theor Appl Genet v. 117:701-709-2008 v.117 no.5. https://doi.org/10.1007/ s00122-008-0811-6

51. Henry RJ, Saini H (1989) Characterization of cereal sugars and oligosaccharides. Cereal Chem 66:362-365

52. Park H, Seib PA, Chung OK (1997) Fortifying bread with a mixture of wheat fiber and Psyllium Husk fiber plus three antioxidants. Cereal Chem 74:207-211. https://doi.org/10.1094/ CCHEM.1997.74.3.207 
53. Gan Z, Ellis PR, Schofield JD (1995) Gas cell stabilisation and gas retention in wheat bread dough. J Cereal Sci 21:215-230. https:// doi.org/10.1006/JCRS.1995.0025

54. Lagrain B, Rombouts I, Brijs K, Delcour JA (2011) Kinetics of Heat-Induced Polymerization of Gliadin. J Agric Food Chem v. 59:2034-2039-2011 https://doi.org/10.1021/jf104201u

55. Katina K (2003) High-fibre baking. Bread Mak. https://doi.org/ 10.1533/9781855737129.2.487

56. Sroan BS, Bean SR, MacRitchie F (2009) Mechanism of gas cell stabilization in bread making. I. The primary gluten-starch matrix. J Cereal Sci 49:32-40. https://doi.org/10.1016/J.JCS.2008. 07.003

57. Horstmann SW, Atzler JJ, Heitmann M et al (2019) Impact of different $S$. cerevisiae yeast strains on gluten-free dough and bread quality parameters. Eur Food Res Technol 245:213-223. https:// doi.org/10.1007/s00217-018-3154-9

58. Hallberg LM, Chinachoti $P$ (2002) A fresh perspective on staling: the significance of starch recrystallization on the firming of Bread. J Food Sci 67:1092-1096. https://doi.org/10.1111/j.1365-2621. 2002.tb09458.x

59. Ozge Ozkoc S, Sumnu G, Sahin S (2009) The effects of gums on macro and micro-structure of breads baked in different ovens. Food Hydrocoll 23:2182-2189. https://doi.org/10.1016/j.foodhyd. 2009.04.003

60. Haskå L, Nyman M, Andersson R (2008) Distribution and characterisation of fructan in wheat milling fractions. J Cereal Sci 48:768-774. https://doi.org/10.1016/J.JCS.2008.05.002

61. Nilsson U, Öste R, Jägerstad M (1987) Cereal fructans: hydrolysis by yeast invertase, in vitro and during fermentation. J Cereal Sci 6:53-60. https://doi.org/10.1016/S0733-5210(87)80040-1

62. Scazzina F, Siebenhandl-Ehn S, Pellegrini N (2013) The effect of dietary fibre on reducing the glycaemic index of bread. Br J Nutr 109:1163-1174. https://doi.org/10.1017/S0007114513000032

63. Fardet A, Leenhardt F, Lioger D et al (2006) Parameters controlling the glycaemic response to breads. Nutr Res Rev 19:18-25. https://doi.org/10.1079/NRR2006118

64. Foschia M, Peressini D, Sensidoni A et al (2015) Synergistic effect of different dietary fibres in pasta on in vitro starch digestion?
Food Chem 172:245-250. https://doi.org/10.1016/J.FOODC HEM.2014.09.062

65. Izydorczyk M, Biliaderis CG, Bushuk W (1991) Comparison of the structure and composition of water-soluble pentosans from different wheat varieties. Cereal Chem 68:139-144

66. Cameron-Smith D, Collier GR, Odea K (1994) Effect of soluble dietary fibre on the viscosity of gastrointestinal contents and the acute glycaemic response in the rat. Br J Nutr 71:563-571. https:// doi.org/10.1079/BJN19940163

67. Johnson IT, Gee JM (1981) Effect of gel-forming gums on the intestinal unstirred layer and sugar transport in vitro. Gut 22:398403. https://doi.org/10.1136/gut.22.5.398

68. Flourié B (1992) The Influence of Dietary Fibre on Carbohydrate Digestion and Absorption. In: Schweizer TF, Edwards CA (eds) Dietary fibre-a component of food: nutritional function in health and disease. Springer, London, pp 181-196

69. Chung HJ, Lim HS, Lim ST (2006) Effect of partial gelatinization and retrogradation on the enzymatic digestion of waxy rice starch. J Cereal Sci 43:353-359. https://doi.org/10.1016/j.jcs.2005.12. 001

70. Sasaki T, Kohyama K (2012) Influence of non-starch polysaccharides on the in vitro digestibility and viscosity of starch suspensions. Food Chem 133:1420-1426. https://doi.org/10.1016/J. FOODCHEM.2012.02.029

71. Karhunen LJ, Juvonen KR, Flander SM et al (2010) A Psyllium fiber-enriched meal strongly attenuates postprandial gastrointestinal peptide release in healthy young adults. J Nutr 140:737-744. https://doi.org/10.3945/jn.109.115436

72. Ellis PR, Apling EC, Leeds AR, Bolster NR (1981) Guar bread: acceptability and efficacy combined. Studies on blood glucose, serum insulin and satiety in normal subjects. Br J Nutr 46:267276. https://doi.org/10.1079/BJN19810032

Publisher's Note Springer Nature remains neutral with regard to jurisdictional claims in published maps and institutional affiliations. 